\title{
The Etiology and Evolution of Fetal Brain Injury
}

\author{
Andrew Macnab1,2 \\ ${ }^{1}$ Faculty of Medicine, University of British Columbia, Vancouver, \\ ${ }^{2}$ Stellenbosch Institute for Advanced Study (STIAS), \\ Wallenberg Research Centre at Stellenbosch University, Stellenbosch, \\ ${ }^{1}$ Canada \\ ${ }^{2}$ South Africa
}

\section{Introduction}

The nine months of intrauterine life are a continuum during which a series of situations and events can occur that result in abnormalities of normal brain growth or injury to the developing brain of the fetus. Genetic mutations and hereditary syndromes can predispose the fetus to intrauterine death, mortality in early life, and various degrees and combinations of brain injury and neurological deficits. Structural brain injury occurs due to a number of well defined and some relatively obscure causes. Premature delivery puts the fetus at risk of complications during birth and in the early days of life that can compromise the brain. Such infants have systems that are physiologically too immature to function normally, making them dependent on a range of care entities many of which are known to have risks associated with their use. The end result especially when prematurity is of extreme degree, is a significant incidence of cognitive and motor deficits. Maternal infection is increasingly recognized to precipitate premature labour and produce inflammatory by-products that cross the placenta and increase the vulnerability of the fetus to brain injury. (Gotsch et al, 2007; Kendall \& Peebles 2005; Mercer 2004) Various pathologies related to the placenta also compromise the well being of the fetus. Impaired fetal growth secondary to placental insufficiency is associated with a reduction in the number of brain cells formed by the time the infant is born; growth retarded infants are at increased risk of hypoxic stress and hypoxic ischemic brain injury due to failure of placental blood flow, gas exchange and fetal oxygen delivery. Suboptimal nutrition also poses the risk of hypoglycaemic brain injury immediately after birth. Post mature infants are at risk from placental failure, hypoxic ischaemic injury and birth trauma. Infants conceived with in-vitro fertilization are at increased risk of neurological disability, especially cerebral palsy. (Stromberg et al 2002) Stroke is a significant cause of neurodevelopmental morbidity in newborn infants that can result in permanent sequelae and may be underreported. (Ozduman et al 2004) The overall incidence of cerebral palsy has not been reduced significantly in spite of advances in obstetric care, and CP remains a significant cause for motor deficits and cognitive disability that become evident in early life and result in permanent disability. 
Hypoxia is central to the genesis of a significant proportion of the brain injury that occurs in the fetus. Compromised oxygen delivery is a particular risk factor during labour and delivery, but the fetus is at risk of brain injury whenever cerebral ischemia occurs as a consequence of impaired cerebral blood flow. After hypoxic ischaemic injury, reperfusion of the brain and any situations that further compromise normal perfusion, oxygen and carbon dioxide transport, or the supply of metabolites required for normal brain function have the potential to complicate recovery, and can also contribute to additional brain injury. (Fellman \& Raivio 1997, von Bell et al 1993) Major mechanisms linked to perinatal brain injury are hypoxic ischemic insults and haemorrhagic brain injury in term infants (those born beyond 37 weeks of gestation) and periventricular haemorrhage and white matter injury (leukomalacia) in preterm infants (those born before 37 weeks of gestation).

Hypoxic ischemic brain injury is estimated to occur in $0.5-0.75$ per thousand deliveries. The pattern and consequences of injury depend on the severity and duration of the insult, the neurovascular and anatomical maturity of the brain which is primarily a factor related to the gestational age of the fetus, and co-related factors such as the presence or absence of infection, problems with fetal nutrition, or pre-existing abnormalities in brain growth and development. Ferriero (Ferriero 2004) has reviewed the gestation specific vulnerability of different regions of the fetal brain and individual cell lines to damage, and the central role of oxidative stress and excitotoxicity in fetal brain injury.

Infants born very prematurely are at particularly high risk for brain injury as brain development in such infants is so immature that they are vulnerable to fluctuations in brain blood flow and oxygen delivery that are insufficient to generate injury in a more mature fetus. Such fluctuations include variations in cerebral venous pressure, the degree of cerebral vasodilatation and constriction, and the distribution of cerebral blood flow, and also systemic alterations in circulating blood volume, or oxygen and carbon dioxide tension. The periventricular area of the immature preterm brain is particularly prone to injury in such ways. Haemorrhage in this area is a major cause of acute brain injury in premature infants, and the cystic changes that develop in consequence (periventricular leukomalacia PVL) frequently result in permanent scarring. This form of periventricular haemorrhage can also be sufficiently extensive that it extends into the ventricles, where the presence of blood within the cerebrospinal fluid is irritant, and as a result often generates ventricular dilatation or causes obstructive hydrocephalus. (Volpe 2001a)

In larger premature infants and those born at term brain injury involving the cortex or basal ganglia predominates; (Okereafor et al 2008) watershed damage in the parasagital areas of the brain results from moderate hypoxic ischaemic insults, and brain stem injury when injury is more profound. (Roland et al 1988) The regionalization of injury is dictated by the selective vulnerability of different areas of the brain which depends largely on differences in metabolic demand, compensatory mechanisms that occur in response to hypoxia, the maintenance of normal levels of substrate delivery (particularly oxygen and glucose), and the maturity and type of brain cells undergoing development at the time of injury.

The immediate clinical effects of hypoxia and ischemia result in an infant who is neurologically depressed at birth, requires resuscitation to initiate breathing and sometimes cardiovascular support to stimulate heart function and ensure adequate blood pressure and circulation. Tone and behaviour are abnormal and an encephalopathy develops in the hours 
or days after birth where neurological abnormalities include problems with level of consciousness, tone, respiratory drive, and coordination of sucking and swallowing, and seizure activity usually occurs. In the longer term the consequences of hypoxic ischemic brain injury vary between death and complete recovery (Perlman \& Shah 2001), with the spectrum of long term brain morbidity ranging from mild motor and cognitive defects to cerebral palsy and severe cognitive disabilities.

Importantly many of the causes of fetal brain injury are avoidable and some are amenable to treatment. The evolution of hypoxic ischaemic brain injury for example has two phases over time. Following the initial insult a 'latent' phase follows that is associated with a transient recovery of cerebral energy metabolism, then hours or sometimes days later a second phase occurs where cerebral energy failure and oedema within the brain cells initially injured compounds the degree of injury. (Gunn 2000) The interval between this biphasic response offers a therapeutic window during which interventions aimed at ameliorating the effects of hypoxia and ischemia are being explored.

\section{Causal mechanisms for structural defects}

Structural development: The structure of the fetal brain evolves throughout intra uterine life. Comprehensive reviews describe the initial proliferation of cells, generation of neurons in the cortical germinal zone, and process of normal brain growth and maturation. (Hatten 2002; Marin \& Rubenstein 2003; Larroche et al 1997; Razic 2002) Normal growth involves a continuum that must be appreciated in order to fully understand the causes, evolution, and consequences of brain deficits associated with abnormalities in fetal brain development. Key influences that determine normal structure include genetic, embryonic, nutritional and environmental factors.

Genetic anomalies are the principal cause of fetal loss. (Heffner 2004) In such circumstances brain abnormalities at a macroscopic and microscopic level are commonly evident. Francis et al (Francis et al 2006) have reviewed the history and molecular genetic advances in cortical development disorders, and use microcephaly to explain the complex mechanisms underlying correct development of the human brain. Where a fetus with a genetic anomaly is born alive there may or may not be structural brain involvement. While many genetic mutations are random most are inherited, although some have variable expression. Environmental factors such as radiation or chemical exposure are uncommon but preventable causes, and parental age plays an important part. (Heffner 2004) Conception is less likely as females and males age, with the proportion of sub-optimal ova and unhealthy structurally abnormal sperm increasing exponentially with age, and there is the well recognized association between age and a number of genetic syndromes such as Trisomy 21 (Down syndrome). Infants conceived with the use of assisted reproductive technology are more likely than naturally conceived infants to have multiple major defects including chromosomal and musculoskeletal defects. (Hansen et al 2002) Some racial groups have a predisposition to specific genetic anomalies associated with structural brain abnormalities e.g. the Irish and Welsh to neural tube defects and hydrocephalus respectively.

Genetic counselling is central to diagnosis and prevention in situations where there is a family history of genetic abnormality with brain injury, birth of a prior infant with an anomaly, or predisposition to a genetic problem due to racial or age related factors. Information from autopsy is important after fetal loss, coupled with placental pathology after unexplained 
stillbirth. An infant born with evidence of brain injury potentially due to a genetic cause requires chromosome studies, placental pathology, and family evaluation in addition to radiological and general and often specific laboratory studies. Prognosis varies; some genetic syndromes are invariably fatal while the spectrum for brain involvement, ability and life expectancy is broad in the remainder, hence the need for identifying the chromosomal anomaly or specific syndrome and making a definite diagnosis wherever possible.

Embryonic development progresses at a rapid pace from the moment first cell division occurs, and a large proportion of the brain's structure is already formed by the time many women become aware that they are pregnant. By the end of the first trimester ( 3 months of gestation) all the main structures of the central nervous system are formed and it is brain growth that follows between this time and fetal maturity (40 weeks). There is always the potential for a variety of factors to negatively impact normal embryonic development, and in-vitro fertilization (IVF) has known associations with multiple pregnancy, infants of low birth weight, and a spectrum of anomalies. (Berg et al 1999, Stromberg et al 2002)

Nutritional deficiencies can negatively impact brain growth, as exemplified by the key role of periconceptual administration of folic acid in the prevention of defective neuropore closure. (Hagberg \& Mallard 2000) This central role in reproductive health, normal neurological system structure, and brain function is underscored by the evolutionary adaptation of skin colour in humans to facilitate folate synthesis. When humankind's African ancestors migrated to less sunny climes, a progressive reduction in skin pigmentation became essential in order for effective folate (and vitamin D) metabolism to occur, as exposure to sunlight and transmission of ultraviolet light through the skin is required for the effective production of both folate and vitamin D. (Jablonski 2006). Dietary intake is also relevant but optimal folate levels for normal fetal neural development are difficult to achieve, especially for sub-populations at particular risk of structural anomalies. Hence, for prevention, the majority of pregnant mothers can benefit from folic acid supplementation, as evidenced by the fall in neural tube defects in populations where food items are now supplemented. Rodent models also provide convincing evidence that iron deficiency alters metabolism and neurotransmission in major brain structures, such as the basal ganglia and hippocampus, and disrupts myelination brain wide. (Lotzoff \& Georgieff 2006) While evidence for the same issues affecting the human fetus is less clear, even the possibility combined with the high worldwide incidence of iron deficiency in pregnancy makes iron supplementation logical to reduce the impact of this wholly preventable form of brain pathology.

Environmental factors relevant as a mechanism for brain damage range in severity due to the high toxicity of some agents, e.g. cocaine, the effect of dosage and cumulative exposure in others such as alcohol, and the frequency of fetal exposure to agents such as nicotine in mothers who smoke. Gestational age plays a role principally in that the fetal brain is most vulnerable during the early stages of structural development. The impact of environmental factors can be multi-factorial with exposure to multiple agents increasing the risk of brain damage, and in some situations a genetic predisposition to the toxic effect of individual agents is evident e.g. related to alcohol.

Perhaps the best known association is between fetal exposure to alcohol and the Fetal Abnormality Spectrum Disorder (FASD). Heavy prenatal alcohol exposure can have serious 
and long-lasting effects on the developing fetal brain, that severely affect the physical and neurobehavioral development of a child. Autopsy and brain imaging studies indicate reductions and abnormalities in overall brain size and shape, specifically in structures such as the cerebellum, basal ganglia, and corpus callosum. A wide range of neuropsychological deficits have been found in children prenatally exposed to alcohol, including deficits in visulospatial functioning, verbal and nonverbal learning, attention, and executive functioning. These children also exhibit a variety of behavioural problems that can further affect their daily functioning. (Riley \& McGee 2005).

The potential for adverse effects on the fetal brain from maternal drug use is exemplified by the effect of cocaine; use of the drug during pregnancy causes structural brain defects; increases the incidence of low birth weight with its attendant risks; and multiple functional deficits manifest once the child is born, some of which persist as learning difficulty into adult life. Sometimes infants exposed to cocaine in utero have ultrasound evidence of cyst formation in the frontal lobes of the brain, basal ganglia, posterior fossa, germinal matrix and septum pellucidum. These are particularly likely following drug use in the first trimester, and probably represent focal necrosis caused by complex vasoconstrictive effects of the cocaine. (Dow-Edwards 1991) This vulnerability of the fetal brain to damage in the first trimester is not unique to cocaine; many drugs and chemical agents cause structural anomalies as this is the time when key structures are being formed.

Maternal smoking increases the risk of an infant being of low birth weight (LBW) two fold; is responsible for $20 \%$ to $30 \%$ of all LBW infants; and causes such infants to weigh $150-250 \mathrm{~g}$ less on average than those born to non-smoking mothers. The adverse fetal effects of smoking are generated through several pathways. Placental function is impaired by vasoconstrictive cigarette smoke metabolites; these can reduce uterine blood flow by up to $38 \%$ depriving the fetus of both oxygen and nutrients. The episodic hypoxia and malnutrition that results underlie the intrauterine growth retardation that occurs in many infants born to smoking mothers. Nicotine is also a fetal neuroteratogen that targets nicotinic acetylcholine receptors in the fetal brain. Changes in cell proliferation and differentiation occur, synaptic activity develops abnormally, and cell loss and neuronal damage occurs. Even in mothers who do not smoke enough for their infants to be of low birth weight, the nicotine levels to which their fetus is exposed are high enough to produce deficits in fetal brain development (Law et al 2003)

Evaluation of structural brain damage: This is a process that combines relevant elements of the infant and maternal medical and family history, physical examination findings, and laboratory and radiological investigations, including: the infant's condition at birth (requirements for resuscitation, APGAR score, and neurological status); general appearance (appropriateness of growth for gestational age, weight, head circumference, and length, and presence of associated defects): neurological status (especially tone, cry, ability to feed, and seizure activity); fetal sonography and MRI; post-natal ultrasound and neuroradiological studies (CT scan MRI); electroencephalogram; chromosome studies; and consultation with medical specialists such as a neonatologist, geneticist and neurologist.

\section{Predisposing factors for fetal brain injury}

Prematurity: Brain injury in the premature infant is an extremely important problem, in part because of the large absolute number of infants affected yearly. (Volpe 1997) Considerable 
research documents that children born very prematurely ( $<32$ weeks gestation) and or/extremely low birth weight $(<1000 \mathrm{~g})$ are at increased risk for neurobehavioral impairments (cerebral palsy, blindness, deafness), lower general intelligence, specific cognitive defects, learning disabilities, and behavioural and emotional problems. Also that the survival rate for extremely preterm infants $(<26$ weeks gestation or with a birth weight of $<750 \mathrm{~g}$ ) is approximately $50 \%$ but that $40 \%$ of survivors do not escape significant deficits. (Anderson \& Doyle 2008) Modern neonatal care entities now enable 75-90\% of preterm infants weighing $<1500 \mathrm{~g}$ at birth to survive in Europe and the USA; however $5-10 \%$ of survivors exhibit cerebral palsy and many have cognitive, behavioural, attention-related or socialization deficits. (Halopainen \& Lauren 2011)

The two principal brain lesions that underlie the neurological manifestations observed in premature infants are periventricular hemorrhagic infarction and periventricular leukomalacia. (Volpe 2001a) In the animal model relatively brief periods of hypoxaemic compromise appear to be more profound in the less mature brain in mid rather than late gestation, when they have significant effects on the fetal brain causing death of susceptible neuronal populations (cerebellum, hippocampus, and cortex) and cerebral white matter damage. (Rees \& Inder 2005) Cerebellar injury is also increasingly recognized (Limperopoulos et al 2009)

Very premature infants are prone to these lesions because the structural anatomy and neurovascular immaturity of their brains predisposes them to injury from hypoxia (inadequate oxygenation) and ischemia (inadequate blood flow) which predispose them to cerebral haemorrhage. The immature brain lacks the duplication of blood supply that develops as a fetus matures and the ability to auto-regulate cerebral blood flow in response to changes in systemic blood pressure. Areas of the brain such as the germinal matrix have vascular complexes that are vulnerable to bleeding when blood pressure fluctuates. Such haemorrhage is common related to asphyxial stress and results in a pattern of injury unique to the preterm infant. In this context, prematurity is certainly the major causal factor of cerebral palsy. However, the literature also indicates that the odds of brain injury become much greater in the fetus in the presence of maternal fever, and from the effects of inflammation, or proven infection, than when the only risk factor is prematurity. (Rees \& Inder 2005)

Premature and low birth weight infants are known to be at increased risk of brain injury as a consequence of intrauterine infection when microglial activation triggers excitotoxic, inflammatory and oxidative damage, (Malaeb \& Dammann 2009) and of developing infections during the newborn period. Their postnatal vulnerability is because they are compromised in terms of how quickly and how effectively they can mount an immune response. This is in large part because bacterial colonization of the gut after birth is essential for digestive function, and for production of vitamin $K$, an essential component of the clotting mechanism without which haemorrhagic disease of the newborn can develop. This bleeding tendency can involve intracranial bleeds of sufficient severity to cause brain damage and even death. As an additional precaution, newborns are routinely given this vitamin prophylacticaly after birth. Risk factors for neonatal sepsis include prolonged rupture of membranes (beyond 18 hours the risk of infection increases 10 fold, and the occurrence of perinatal asphyxia adds additional risk); and maternal colonization with group B Streptococcus and urinary tract infection (Gerdes 2004). Prophylactic antibiotics are 
used in anticipation of sepsis as by the time confirmatory tests (bacterial cultures) are positive the risks of increased morbidity or mortality rises. This is due in large part to the risk of dissemination of infection e.g. to the brain and meninges causing meningitis, or because of the greater levels of toxic metabolites released when the higher counts of bacteria present as a consequence of treatment being delayed are killed by therapy.

Brain injury in premature infants as a consequence of periventricular haemorrhagic infarction and periventricular leukomalacia may be preventable. Logical approaches would include measures to prevent germinal matrix-intraventricular hemorrhage, prevent or manage impairments of cerebrovascular autoregulation and cerebral blood flow, and the use of agents such as free radical scavengers to interrupt the cascade to oligodendroglial cell death. (Volpe 2001b). Importantly, the consequences of being born prematurely also predispose infants born following fetal brain injury to additional compounding stresses and insults in the newborn period; such events also pose a threat of increased morbidity and long term neurological compromise to those who have intact brains at birth. Hence the high overall risk of motor, cognitive, and educational defects in those that survive being born prematurely. (Rees \& Inder 2005, Anderson \& Doyle 2008)

Low birth weight (LBW) infants are those born weighing $<2500 \mathrm{~g}$. LBW infants comprise both those born prematurely but appropriately grown for gestational age and those who are small because of intrauterine growth retardation. LBW infants accounts for $7.6 \%$ of all live born infants and $65 \%$ of deaths in the United States occur among LBW infants due to multiple risk factors related to the underlying cause of their small size. In most instances intrapartum morbidity is higher amongst this group, and many are also at risk during the newborn period. Brain injury in a fetus of LBW is potentially caused by many factors; where placental dysfunction is the underlying cause, acute problems may compromise placental gas exchange and precipitate fetal hypoxic ischemic stress.

Small for gestational age (SGA) infants are those with intrauterine growth retardation who when born are below the $10^{\text {th }}$ centile for weight; where length and head circumference are also similarly compromised, such infants are known as symmetrically growth retarded and brain size and function are usually adversely affected. Long term deficits in neural connectivity are described (Rees \& Inder 2005) and cognitive problems are common in surviving infants. SGA infants have no glycogen stores in their liver at birth and are hence prone to hypoglycaemia that can compound pre-existing fetal brain injury. In utero maternal blood glucose levels determine fetal levels, and, in addition, the fetal brain is able to metabolize lactate as an alternative energy source. However, this pathway is down regulated after birth once oral feeding begins. As a group, surviving SGA infants are at particular risk in adult life of developing cardiovascular disease, hypertension and stroke.

Maternal Illness during pregnancy poses a risk for fetal brain injury. Many are specific to pregnancy such a pre-eclamptic toxaemia, but others pre-exist prior to pregnancy and of themselves, or because of treatment they require, have the potential to cause damage, or predispose the fetus to situations such as prematurity or low birth weight that carry independent risks for neurological morbidity. Examples that pose clear risks for the fetal brain and neurological system are anticonvulsant medications and cancer therapies (Halopainen \& Lauren 2011). But, while there is general recognition that any medication should be considered carefully in the context of pregnancy and wherever possible be discontinued, in some instances the wellbeing of the mother has to be weighed against the 
potential for risk to the fetus. However, not infrequently drugs in common use that are initially identified as problematic sometimes only come to be recognized in their true context after some years of use and appropriately rigorous research and review.

A case in point relates to selective serotonin reuptake inhibitor (SSRI) use during pregnancy and the effects of these agents on the fetus and newborn infant. Serotonin is a neurotransmitter that appears very early in fetal life and has a broad role in brain morphogenesis. Studies to evaluate the neurotoxicity of SSRI's identified a number of agespecific and site-specific effects in the fetal rat brain, especially related to the limbic system (Lattimore et al 2005). Subsequently a number of adverse effects were identified to occur in human newborns, and there was a clear association with low birth weight (Oberlander et al 2006), the need for special care in the newborn period, and an apparent increase in the incidence of prematurity (Lattimore et al 2005). This led to calls for SSRI use to be reconsidered in pregnancy, although there was debate as to whether the effects observed in the newborn were attributable to acute cessation of exposure (withdrawal) or a direct prenatal effect. However, this class of medications is widely prescribed to treat a number of psychiatric disorders, and is of particular value in severely depressed patients in pregnancy (Austin 2006). Hence, following studies of neonatal outcome and meta-analysis of existing research, the recommendation now is that the decision whether or not to discontinue SSRI use in pregnancy has to be made on a case by case basis. (Oberlander et al 2006; Lattimore et al 2005; Austin 2006)

Another challenge for care givers and concern for pregnant mothers is that the literature indicates that something as common as maternal fever during intercurrent illness can pose problems. A maternal temperature of $38{ }^{\circ} \mathrm{C}$ or higher is an independent risk factor for significantly increased fetal morbidity, and the specific risk of brain damage resulting in Cerebral Palsy is increased many fold by maternal fever. (Gotsch et al 2007; Kendall \& Peebles 2005; Barks \& Silverstein 2002; Grether \& Nelson 1997)

Some infections are well known to cause brain injury. Those known collectively as the TORCH group (toxoplasmosis, cytomegalovirus and herpes simplex) are examples. (Hagberg \& Mallard 2000) Some viral infections are associated with stillbirth, and when infants are born alive many have systemic effects due to the infectious process. Parvovirus B19 infection is an example of an illness that has been associated with severe fetal complications; fetal involvement can result in vasculitis that causes pathological changes in the central nervous system which can include stroke. (De Haan et al 2006) Fetal outcome may be normal but anaemia, hydrops fetalis and stillbirth also occur. Approximately 30$50 \%$ of pregnant women are nonimmune. Fetal infection in the first trimester poses the greatest risk. Factor V Leiden mutation can lead to activated protein $\mathrm{C}$ resistance which increases the risk of thromboembolism, particularly in the presence of dehydration, asphyxia and infection. Maternal infections as varied as malaria and syphilis adversely affect the fetal brain, and rubella (German measles), varicella (chickenpox) and cytomegalovirus, and labour and delivery complicated by chorioamnionitis and FIRS (Garite 2001; Wu et al; 2003; Bashiri et al 2006) are associated with an increased risk of cerebral palsy and a range of illness specific central nervous system effects. However, upper respiratory tract infections and gastroenteritis, which are common and often a concern to pregnant women, are not. (O'Callaghan et al 2011). 


\subsection{Fetal inflammatory response syndrome (FIRS)}

Inflammatory mediators are known to precipitate premature rupture of the membranes and preterm labour, inflame and cross the placenta, and increase the risk of fetal brain injury and cerebral palsy (O'Callaghan et al 2011). Recent literature uses the term Fetal Inflammatory Response Syndrome (FIRS). (Khwaja \& Volpe 2008; Back \& Rivkees 2004; Gotsch et al 2007; Bashiri et al 2006; Kendall \& Peebles 2005) FIRS is characterized by systemic inflammation, activation of the innate fetal immune system, and elevation of fetal plasma cytokines. Cytokines are small, peptides or glycoproteins secreted de novo in response to inflammation/infection or other immune stimulus. Usually cytokine production is responsible for the generation of a normal immune response, but in the immature fetus or premature infant born after exposure to FIRS the complex effects of cytokine activity significantly increase infant morbidity and mortality, (Gotsch et al 2007; Bashiri et al 2006; Barks \& Siverstein 2002) because the balance of these agents is imperfectly controlled.

Cytokines such as Interleukin -1, -3, and -6, and Tumour Necrosis Factor mediate and regulate immunity, inflammation, and haematopoiesis (blood cell production), and are central to the mechanism for elevation of temperature and stimulation of the bone marrow to produce white blood cells in response to infection. (Bashiri et al 2006; Kendall \& Peebles 2005; Barks \& Silverstein 2002) Importantly, many cytokines are also vasoactive products that increase the vulnerability of the premature fetal brain to hypoxic ischemic injury, and substantial evidence indicates that when a fetus is exposed to intramniotic inflammation there is an increased risk for direct brain injury that can cause short term morbidity and cerebral palsy. (Lee et al 2007)

In the presence of inflammatory cytokines, focal variations in fetal brain perfusion occur that result in local ischemia followed by reperfusion; these perturbations cause cumulative injury to the white matter due to the primitive neuro-vascular architecture, immature autoregulatory control mechanism, and sensitivity of maturational dependent cells to free radical damage in the immature brain (Volpe 2001b) The germinal matrix is particularly vulnerable to variations in brain blood flow and blood pressure; consequently, periventricular hemorrhage is all the more likely to occur in the preterm fetus exposed to FIRS; such haemorrhage may extend into the ventricular system to cause intraventricular hemorrhage. The literature emphasizes "the synergistic role of inflammation and hypoxia and ischemia when they occur together", and the higher incidence of hypoxic ischemic brain damage that results in a fetus exposed to maternal inflammation/infection.

The literature also supports a role for inflammatory mediators in the mechanisms of preterm premature rupture of membranes (PPROM), premature labour and delivery, and links "maternal infection and pro-inflammatory mediators in the neonatal systemic circulation with an increased risk of PVL and/or spastic diplegia." (Back 2004; Bashiri et al 2006; Barks \& Silverstein 2002, Lee et al 2007; Grether 1997; Mercer 2004; Asrat 2001) Maternal cytokines are able to cross the placenta, enter the fetal circulation, cross the brain blood-brain barrier, and produce an inflammatory response in the white matter of the fetal brain which leads to brain damage. (Malaeb \& Dammann 2009) Also, the incidence of fetal distress (Kilbride \& Thibeault 2001) and hypoxic insults (Garite 2001) is higher following PPROM than in pregnancies with preterm labor and intact membranes. This is largely because of the increased risk of cord compression (Garite 2001; Mercer 2004; Kilbride \& Thibeault 2001; 
Ehrenberg \& Mercer 2001) due to low amniotic fluid (oligohydramnios) as a consequence of membrane rupture, although chorioamnionitis and placental dysfunction may also be contributory. FIRS has been observed in fetuses with preterm labour with intact membranes, preterm prelabour rupture of the membranes, where there is proven fetal viral infection, and also where no microbial invasion is proven. In addition, cytokine release occurs in the fetus following contamination in the birth canal after membrane rupture. Inflammatory products entering the fetal lung then pass into the blood stream and generate an inflammatory response and systemic cytokine release in the fetus.

FIRS has been proved in a series of research studies to be a risk factor for short term perinatal morbidity after adjustment for gestational age at delivery, and also for development of long term sequelae, including brain damage (Gotsch et al 2007) "Intrauterine infection/inflammation is one of the most common causes of neonatal complications including preterm delivery, and considered to be the leading identifiable risk factor for cerebral palsy." (Bashiri et al 2006) Epidemiological evidence suggests that exposure to a combination of infection and hypoxic-ischaemic insult dramatically increases the risk of developing cerebral palsy compared with either insult alone. (Kendall \& Peebles 2005) Cytokine mediated brain damage is known to occur as a direct result of an inflammatory process.

In addition to direct cytokine mediated brain damage circulating cytokines also compound the effects of any hypoxic ischemic stress experienced by the fetus. Consequently the severity of any resultant hypoxic ischemic brain damage is increased, particularly in the premature brain. (Gotsch et al 2006; Kendall \& Peebles 2005) Thus causal mechanisms for the higher incidence of periventricular leukomalacia in a preterm fetus with FIRS include:

- maturation-dependent factors that render the premature infant's brain exquisitely sensitive to the occurrence of white matter injury;

- fetal distress being more common following PPROM (intrapartum fetal heart decelerations are seen in over $75 \%$ of patients);

- the higher incidence of hypoxic ischemic brain damage occurring in affected fetuses;

- reduction by cytokines of the threshold at which hypoxia becomes neurotoxic;

- the synergistic effect of inflammation with hypoxia and ischemia when they occur together;

In the context of limiting brain injury, management of cases of FIRS requires consideration of the maturity of the fetus and a balance of the risks of treating the mother and expediting delivery. "Fetal microbial invasion that results in a systemic fetal inflammatory response can, in the absence of timely delivery, progress to cause organ dysfunction, shock and perhaps death." (Gotsch et al 2007) However, the risks of brain injury associated with being born prematurely have to be weighed against those that exist from remaining in utero. In practice specialists in obstetric and newborn care must together evaluate the relative risks and act accordingly. The incidence of infection seems greatest in the first 72 hours following PPROM. (Kilbride \& Thibeault 2001) Immediate induction of labor, compared with expectant management, results in lower rates of chorioamnionitis, fewer babies requiring admission to neonatal ICU, and fewer requiring treatment with antibiotics for suspected sepsis with this approach. The literature states: "For the premature fetus, once clinical chorioamnionitis occurs, rates of sepsis, pneumonia, respiratory distress syndrome and 
death are all increased by 2-4 fold and long-term neurologic injury is substantially more likely to occur."(Asrat 2001) There appears to be no role of expectant management in any patient with PPROM beyond 34 weeks gestation; (Canavan et al 2004) and: At 34-36 weeks gestation, the risk of severe neonatal morbidity and mortality with expeditious delivery is low. Conversely, conservative management is associated with an 8 fold risk of amnionitis; hence these women are best served by expeditious delivery with labour induction. (Mercer 2004) Even at 32 weeks of gestation, premature infants can be expected to have a $92 \%$ intact survival; it is when pregnancy is less advanced that the pros and cons of initiating delivery discussed in the literature have to be considered. The literature also indicates strategies that can be used to down-regulate the inflammatory response and treat mothers who have the signs and symptoms suggestive of infection. Some antibiotic therapies will reduce cytokine production; (Gotsch et al 2007; Kilbride \& Thibeault 2001) also, because of the independent association of elevated maternal temperature with worse fetal outcome, appropriate management and control of fever is also cited as a treatment of potential benefit. (Gotsch et al 2007; Kendall \& Peebles 2005)

\subsection{Hypoxia}

As the physiologist Haldane said: "Hypoxia not only stops the machine it wrecks the machinery." (Haldane 1922) A healthy fetus can respond to, and tolerate, the early effects of hypoxia and the degree of acidosis that occurs initially in response to the associated retention of carbon dioxide. In addition, once significantly stressed, the fetus has the physiologic ability to preferentially perfuse the deep structures of the brain with the highest metabolic rate when systemic acidosis becomes more severe. However, this compensation ultimately fails if the ongoing hypoxia remains unrecognized and unrelieved over the course of an hour or more, and the end result is extensive grey matter damage. In addition to this partial and prolonged pattern of hypoxic ischaemic injury, situations occur where the event is more acute and profound in nature. With such insults, acidosis develops relatively abruptly, little or no compensatory redistribution of blood to the deep structures of the brain occurs, and brain injury happens over a much shorter time frame.

Distinction between these two patterns is important from a preventive, diagnostic and prognostic standpoint and over issues of causation in a medico-legal context. Modern neuroimaging (CT and MRI) is the definitive way to distinguish between them based on the selective patterns of brain damage caused. Following partial and prolonged hypoxia/ischemia, the compensatory redistribution of blood results in the brain's cortical areas being less well perfused and hence the predominant regions damaged, and there is also associated hypoxic ischemic injury of multiple organs other than the brain. Where the insult is acute, near total (or profound) in nature, the deep structures of brain (thalami and basal ganglia) are predominantly damaged because there is no time for effective redistribution of cerebral blood flow to maintain their perfusion. (Roland et al 1998; Cowan et al 2003) Basal ganglia injury often predominates (Logitharajah et al 2009) and is most common in infants with acidemia and HIE. (Ruis et al 2009) Brainstem injury can be associated with severe basal ganglia, white matter and cortical injury, (Logitharajah et al 2009) and non survival. (Roland et al 1988) Secondary multi-organ injury may still occur to some degree but is usually mild or absent. 
A recent review identified 5 sub-patterns of acute near total injury. (Okereafor et al 2008) In pattern 1, basal ganglia and thalami lesions were associated with severe white matter damage; pattern 2 had basal ganglia and thalami lesions with mild or moderate white matter changes; pattern 3 had isolated thalamic injury; pattern 4 moderate white matter damage only; and pattern 5 mild white matter lesions or normal findings. In 93\% of infants with patterns 1 and 2 the internal capsule was abnormal $-86 \%$ of them died or developed cerebral palsy. Infants with patterns 3 and 4 developed developmental delay and diplegic cerebral palsy respectively. Those with pattern 5 had normal outcomes. Case infants were significantly more likely of African descent, born to pluriparous or hypertensive mothers, or involve uterine rupture following previous caesarean section or undiagnosed breech presentation accompanied by prolapse of the umbilical cord.

The time line of acute near-total hypoxic ischemic events can be extrapolated from data obtained in animal studies. In these studies, monkeys exposed to complete, i.e. total hypoxia and ischemia (generated experimentally by ligating the umbilical cord and preventing any respiration), could tolerate 10 minutes of hypoxic ischemic insult without permanent effects if they were delivered/resuscitated immediately after this time. Where the hypoxic ischemic event was allowed to continue beyond this period for an additional 10 minutes a cumulative increase in the level of neurological damage was then evident. Where the event extended beyond 20 minute, the fetal monkeys died, in spite of delivery/resuscitation.

In applying this data to the human fetus, it is recognized that what occurs most often is a near total (profound) interruption of brain blood flow and oxygen delivery, rather than an event where hypoxia and ischemia are absolutely total in nature. Hence the time-line for tolerance of such events, and the period over which brain damage evolves, are accepted as being longer than in the landmark animal studies conducted by Meyers. (Meyers 1973; Meyers 1975a; Meyers 1975b; Ginsberg \& Meyers 1974) For this reason, it is generally agreed that approximately 15 minutes, and possibly up to 20 minutes, of sudden profound asphyxia can be tolerated by the human fetus prior to brain damage beginning (in contrast to the ten minutes seen in the animal model). Then, after this 'grace' period, damage to the brain begins to occur and over a further period of 15 to 20 minutes the extent and severity of injury becomes progressively more profound over time. And beyond this period, a human fetus is usually born dead. It is also important to recognize that the principal mechanism that causes asphyxial brain injury in the fetus is cerebral ischemia caused by the severe reduction in cerebral blood flow that occurs as a result of hypoxic myocardial depression significantly reducing cardiac output. The fetal heart has a fixed stroke volume, which means that cardiac output and the amount of blood supplied to the brain is determined by the rate of heart contraction. With hypoxia and acidosis, myocardial depression leads to a reduction in heart rate; and significant slowing of the fetal heart (bradycardia) equates with a proportional reduction in cardiac output and reduction in cerebral blood flow.

The relationships between the pattern and time course of an asphyxial insult with the site of brain injury and type of disability that results have been summarized by Robertson and Perlman (Robertson and Perlman 2006). Acute, near-total insults of moderate degree with injury to the basal ganglia and thalami result predominantly in athetoid or dystonic cerebral palsy with intact or mildly impaired cognitive development. When severe and prolonged acute insults damage the cerebral cortex in addition to deep brain structures severe spastic 
quadriplegia results, with associated cortical visual impairment, microcephaly and significant cognitive deficits. Prolonged partial insults of moderate degree with injury to watershed regions result in moderate spastic quadriplegia with variable cognitive deficit, but when severe, with extensive cortical brain involvement, result in spastic quadriplegia, severe cognitive impairment, cortical visual impairment, and microcephaly.

Periventricular leukomalacia (PVL) Is predominately, but not exclusively, a condition affecting the preterm infant. PVL can develop during fetal life and in the newborn period. The primary mechanism is hypoxic ischemic injury, and the ischemic component (period of inadequate blood flow) is generally regarded as the major mechanism of injury. Neurobiologic research has shown that maturational dependent oligodendroglial precursor cells are a major target in PVL, and exquisitely vulnerable to damage by free radicals generated during ischemia/reperfusion. (Volpe 2001b) The premature infant has an immature pattern of brain blood supply and a reduced ability to control brain blood flow. (Khwaja \& Volpe 2008; Back \& Rivkees 2004) PVL develops after periods of abnormally low blood flow in the cerebral white matter in areas where there are arterial end zones and border zones present, due to the immaturity of a preterm infant's neurovascular development. Autoregulation of cerebral blood flow is also often impaired in such infants; and where systemic hypotension occurs or there are episodes of fluctuant or inadequate cerebral blood flow for any reason, hypoxic ischemic brain damage can occur involving the vulnerable periventricular areas. (Volpe 2001a). Where a mother has prolonged premature rupture of the membranes (PPROM), her fetus is recognized to have an increased risk for a number of complications that can cause brain damage. Although not every fetus is affected directly or indirectly by the inflammatory cytokines generated under such circumstances, where such brain damage does occur this often manifests as PVL (Back \& Rivkees 2004; Gotsch et al 2007)

PVL is associated with Intraventricular haemorrhage (IVH) in approximately $25 \%$ of cases; the pathogenesis of IVH is usually multifactorial. See Table 1.
- $\quad$ Fluctuating cerebral blood flow
- Increased cerebral blood flow
- Increased cerebral venous pressure
- Decreased cerebral blood flow followed by reperfusion
- Disorders of coagulation, platelet function and capillary integrity
- Vulnerability to hypoxic ischaemic injury

Table 1. The major pathogenic factors for IVH (Modified from Volpe 2001a)

Infants with PVL secondary to significant intrapartum hypoxic ischaemic injury will usually be abnormal on neurological exam at birth; PVL acquired intrapartum may manifest as lower limb weakness evident in the first weeks of life. (Volpe 2001a) PVL can be aggravated by or generated due to postnatal events. The commonest clinical situation in which the most important pathogenic factors combine to generate sufficient ischemia to cause PVL is when a sick preterm infant requires mechanical ventilation; i.e. vascular anatomic factors, physiologic factors, the pressure passive nature of the immature cerebral circulation, systemic variations in blood pressure, and the effects of hypocarbia (Khwaja \& Volpe 2008; Volpe 2001a). If infection is the cause for assisted ventilation being required or if morbidity 
from a prior infection is superimposed, the probability of ischemia and/or haemorrhage compromising the periventricular vasculature is much greater.

Many infants born with PVL have a normal neurologic outcome. Those who have brain injury sufficient to generate permanent sequelae exhibit a range of problems that manifest with varying degrees of severity; including intellectual and visual deficits that are usually superimposed on spastic paresis involving the extremities where the lower limbs are predominantly affected.

Hypoxic ischaemic encephalopathy (HIE) is "an acute non-static encephalopathy caused by intrapartum or late antepartum brain hypoxia and ischemia"; (Robertson \& Perlman 2006) this clinical state evolves during the first days of life following significant hypoxic ischaemic insult, and is a major predictor of neurodevelopmental disability.(Ferriero 2004) Prospective studies incorporating MRI suggest that the majority of cases of encephalopathy occur as a result of brain injury that occurs at or near the time of birth. (Cowan et al 2003) After a severe insult depression of consciousness is common in the first hours, hypotonia and reduced movement occur, particularly with cortical injury, and the onset of seizure activity is common.

The probability that hypoxic ischaemic brain injury will result in permanent neurological consequences is recognized to increase with the severity and duration of HIE. The distinguishing features of three clinical stages of HIE (mild, moderate and severe) were classified by Sarnat and Sarnat (Sarnat and Sarnat 1976) based on observations in 26 full term newborn infants exposed to perinatal asphyxia. See Table 2.

Infants who develop HIE exhibit a range of alterations in conscious level and behaviour from a hyper-alert state through irritability to lethargy and obtundation. Disorders of tone are also evident that again range from an increase through to a marked decrease. And a variety of abnormal movements occur from tremors and jitteriness through to frank seizures. Other clinical manifestations include apnoea (temporary cessation of breathing) with bradycardia and impaired oxygen saturation, shrill cry, feeding difficulty (mainly due to poor coordination of suck, but occasionally due to brain stem damage), exaggeration of the Moro and deep tendon reflexes, and decerebrate or decorticate posturing. The severity of HIE symptoms depends on the timing and duration of the causal insult. (Rees \& Inder 2005) Each infant's clinical state evolves following the hypoxic episode, often with marked changes evident initially over the course of hours, and then later over days or weeks, necessitating serial examination and evaluation with EEG and neuroimaging.

An encephalopathic state develops after 1-6 per 1000 live births. Mortality is high (15-20\% in some series) with most deaths occurring within a month of injury due to associated multiple organ failure or termination of care. In about $25 \%$ of cases permanent neurologic deficits remain. Not all cases of neonatal encephalopathy are due to anoxia or hypoxic ischaemic injury; (Ferriero 2004; Volpe 2001a) but epidemiological studies confirm the association of HIE with pregnancy related risks (maternal pre-eclamptic toxaemia, hypertension, FIRS, and infertility treatment) and a range of intrapartum risk factors that predispose the fetus to hypoxic ischaemic brain injury. Postnatal aggravation of intrapartum acquired injury occurs relatively rarely $(10 \%)$, but is a preventable component in many instances. Prevention centres on anticipating and limiting the adverse effects on the brain of fluctuations in 
cerebral perfusion, respiratory distress, sepsis, metabolic instability, and any situation that increases oxygen and energy demands (e.g. as occur with protracted seizures).

\begin{tabular}{|c|c|c|c|}
\hline STAGE & CLINICAL FEATURES & EEG & $\begin{array}{l}\text { DURATION AND } \\
\text { OUTCOME }\end{array}$ \\
\hline 1 - Mild & $\begin{array}{ll}\text { - } & \text { State - Hyper-alert, } \\
\text { - } & \text { irritable, jittery } \\
\text { - } & \text { Tone - normal } \\
\text { - } & \text { Suck - weak } \\
& \text { Seizure - none }\end{array}$ & - normal (awake) & 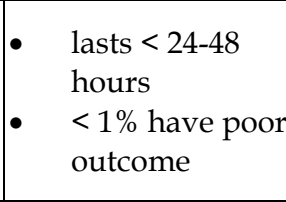 \\
\hline 2 - Moderate & $\begin{array}{ll}\text { - } & \text { State - Lethargic, } \\
\text { obtunded } \\
\text { - } & \text { Tone - mild hypotonia } \\
\text { - } & \text { Suck - weak or absent } \\
\text { Seizures - common: } \\
\text { variable (focal or } \\
\text { multifocal) }\end{array}$ & $\begin{array}{ll}\text { Early - low } \\
\text { voltage } \\
\text { Later - periodic } \\
\text { discharges, focal } \\
\text { spike and wave }\end{array}$ & $\begin{array}{ll}\text { - } & \text { lasts days } \\
& 20-40 \% \text { poor } \\
\text { outcome }\end{array}$ \\
\hline 3 - Severe & $\begin{array}{ll} & \text { State - } \\
& \text { Stuporous/Comatose } \\
\text { - } & \text { Tone - flaccid } \\
\text { - } & \text { Suck - absent } \\
\text { - } & \text { Seizures - decerebrate } \\
& \text { posturing } \\
\end{array}$ & $\begin{array}{ll}\text { Early - periodic } \\
\text { pattern } \\
\text { Later - } \\
\text { isopotential }\end{array}$ & $\begin{array}{l}\text { lasts days to } \\
\text { weeks } \\
100 \% \text { poor } \\
\text { outcome }\end{array}$ \\
\hline
\end{tabular}

Table 2. The Sarnat Score (modified from Sarnat and Sarnat (Sarnat \& Sarnat 1976))

Seizures: major causes of seizures include brain malformation, structural injury, or reversible metabolic disorders. The clinical signs vary from subtle movement disorders to focal or generalized brief or sustained convulsive activity. Abnormal movement often involves the eyes (blink, staring, horizontal tonic deviation), mouth (lip smacking or sucking, tongue thrusting), extremities (bicycling/rowing or jerking), or respiratory muscles (apnoea). Variations in heart rate occur (tachycardia and bradycardia), often with colour change due to a degree of oxygen desaturation. Focal clonic seizures may imply brain damage due to arterial or venous infarction. The suspicion that clinical signs represent seizures should be confirmed by electroencephalogram (EEG). MRI can help distinguish between seizures due to hypoxic-ischemic events and those caused by other forms of metabolic or genetic disease, (Huang \& Castillo 2008; Alkalay 2005; Alkalay et al 2005a; Alkalay et al 2005b; Barkovich et al 1998; Efron et al 2003) and provides information on the extent of traumatic and infectious causes. Preventable/reversible causes of seizures include hypoglycemia, hypocalcemia, hyponatraemia, hypoxemia, and acidosis. However delayed treatment probably increases the risk of residual consequences; and considerable stresses are placed on the brain by the high oxygen and substrate requirements implicit when seizures are prolonged. (Tasker 2001) However, seizures do not always imply poor neurodevelopmental outcome for affected newborns.

The number of term infants who survive HIE is lower than those who are extremely premature, but the proportion who survive with long term sequelae is higher; such infants require follow up and management of their handicaps: regimens to do this have been 
described. (Robertson \& Perlman 2006) Outcome prediction for infants with HIE has been proposed using defined periods (0-6 hours after birth, 6-72 hours after birth, and before discharge) and clinical, imaging and electrophysiological predictors, and neurological examination criteria. The purpose is to rationalize hypothermia and other intervention therapies, including the withdrawal of support, and improve knowledge related to the continuum that HIE and the evolution of the brain injury that underlies its pathology represents. (Perlman \& Shah 2011).

Entities aimed at minimizing the effects of HIE are evolving. Controlled reoxygenation to avoid hyperoxia is one. Drugs with potential as therapies include novel anti-oxidative agents such as $\mathrm{N}$-acetylcysteine, neuroprotective agents targeted at glutamate receptors and others such as magnesium sulphate, endocannabinoids; (Halopainen \& Lauren 2011; Todd et al 2011) and controlled hypothermia shows promise. (Vannucci \& Perlman 1997; Gunn \& Gluckman 2007; Ferriero 2004; Schulzke et al 2007; Higgins et al 2006). The concept for cooling being beneficial during recovery from encephalopathy stems from animal studies and the neuroprotective effect of hypothermia in cases of near-drowning in children and during cardiac surgery involving periods of cardiac arrest. Early studies using short periods of cooling in encephalopathic newborns had limited and contradictory results; recent experimental studies are more promising having shown that moderate cerebral hypothermia initiated as soon as possible after the initial insult, before the onset of secondary energy failure, and continued for 48 hours or more is associated with neuroprotection (Gunn \& Gluckman 2007) Randomized clinical trials that used either systemic cooling or selective head cooling in encephalopathic neonates also suggest moderate hypothermia is safe, (Gunn \& Gluckman 2007; Feigin et al 2004) and that newborns with moderate encephalopathy are better from a neurodevelopmental perspective than normothermic controls at the same age in early infancy. (Gunn \& Gluckman 2007) However, a 2005 working group (Higgins et al 2006) while seeing this as a "potentially promising therapy", identified significant unresolved issues; central to these is how to identify which babies are most likely to benefit (Gunn \& Gluckman 2007) and the relative safety and benefit of different techniques of cooling. (Gunn \& Gluckman 2007; Schulzke et al 2007). Hence studies are ongoing, as with any experimental therapy, the potential for good results must be balanced against any adverse systemic effects and long term follow up data obtained.

One element that would aid in this process and documenting the severity and evolution of brain injury is novel monitoring techniques that allow oxygen supply and demand and cerebral haemodynamics to be evaluated. An example of a technology that has been tried in this regard and continues to show potential is near infrared (NIR) spectroscopy (NIRS). NIRS is an established non-invasive optical technology using energy from the NIR spectrum to monitor changes in local blood flow and hemodynamics non-invasively within the microcirculation, and detect differences in tissue oxygen delivery, consumption and utilization. NIRS has been used to study healthy and injured brain (Wyatt 1993; Chen et al 2002; Sakatani et al 1998; Lin et al 2009), and is a promising tool for determining optimal cerebral perfusion pressure for patients with acute brain injury (Brady et al 2007). Comprehensive reviews describe the basic principles, limitations and parameters that can be quantified. (Ferrari et al 1992; Wolf et al 2007; Ferrari et al 2004; Rolfe 2002; Macnab 2009). NIR spectroscopy uses energy from the NIR spectrum to follow variations in the 
concentration of oxygenated $\left(\mathrm{O}_{2} \mathrm{Hb}\right)$ and deoxygenated $(\mathrm{HHB})$ haemoglobin, and employs many of the fundamental principles of physics relating to the transmission of light through tissue. However, it is the unique combination of the transparency of tissue to NIR wavelengths and the specific absorption spectra of oxygenated and deoxygenated haemoglobin that form the basis of biomedical applications of NIR spectroscopy. Reviews describe the development of instrumentation, the technical specifications of individual units and recent advances in the technology. (Ferrari et al 1992; Wolf et al 2007; Ferrari et al 2004; Rolfe 2002; Macnab 2009; Yodh \& Boas 2003; Hoshi 2007) Because the initial concentration of $\mathrm{O}_{2} \mathrm{Hb}$ and $\mathrm{HHb}$ in the tissue being monitored is unknown, only absolute changes in concentration relative to the initial baseline concentration can be derived using conventional NIR spectroscopy. However, with real time sampling and graphic conversion of data, the patterns and magnitude of change derived provide valuable information, as they can be used to infer physiologic change occurring within the tissue interrogated. (Hamaoka et al 2007; Ferrari et al 2011; Wolf et al 2007) Examples of such changes include:

- $\quad$ an increase or decrease in $\mathrm{O}_{2} \mathrm{Hb}$ (an indirect measure of oxygen content);

- $\quad$ an increase or decrease in the total haemoglobin - $\mathrm{tHb}\left[\mathrm{O}_{2} \mathrm{Hb}+\mathrm{HHb}\right.$ (change in blood volume);

- $\quad$ an abrupt decrease in $\mathrm{O}_{2} \mathrm{Hb}$ with simultaneous increase in $\mathrm{HHb}$ (ischemia); and

- a gradual decrease in $\mathrm{O}_{2} \mathrm{Hb}$ and increase in $\mathrm{HHb}$ (hypoxia).

The absolute ratio of $\mathrm{O}_{2} \mathrm{Hb}$ to $\mathrm{tHb}$ can be determined using spatially resolved spectroscopy (SRS), (Murkin \& Arango 2009; Suzuki et al 1999) which requires an instrument to have either a multiple segment photodiode chip or an array that has multiple emitter-detector distances. Such pathlength geometry allows light detection at two or more different distances from the emitter, which enables the absolute ratio of $\mathrm{O}_{2} \mathrm{Hb}$ to $\mathrm{tHb}$ to be determined, and a calculation of tissue oxygen saturation to be made. On instruments with SRS capability this parameter is variously referred to as the 'tissue oxygenation index' (TOI), 'tissue saturation index' (TSI \%), or 'mean tissue Hb saturation' (rSO2). (Shadgan et al 2009; Owen-Reece et al 1999; Tobias 2006)

NIR spectroscopy is an attractive technology for clinical monitoring because it is non-invasive, uses a non-toxic energy source, and can monitor physiologic change continuously with high temporal resolution. (Ferrari et al 2004; Rolfe 2000) Investigators value the ability to make comparison between sites of measurement using multichannel instruments, and conduct studies in real time. Monitoring in real time in situations where being able to identify the onset of adverse events allows potentially remediable intervention is attractive clinically, particularly where the brain or spinal cord are affected (e.g. by the onset of ischemia). (Murkin \& Arango 2009; Macnab et al 2002, Macnab et al 2003) In brain studies NIRS has yielded "much credible and some important clinical research data," (Simonson \& Piantadosi 1996) and a threshold for cerebral ischemia has been defined using SRS. (Al-Rawi 2005)

Early studies in newborn infants showed that changes in cerebral blood flow and blood volume occurred in the hours following hypoxic ischemic brain injury. (Wyatt 1993; von Bel 1993; Fellman \& Raivio 1997) Stresses that most sick premature newborn infants experience, including painful stimuli and loud noise, also affect cerebral haemodynamics, (Gagnon et al 1999) and over time such disturbances have been suggested as a mechanism that might explain the neurological morbidity evident in many infants who do not have specific illness 
or adverse events to which to attribute their motor or cognitive problems. Auditory evoked changes in cerebral oxygenation are evident after hypoxic ischemic injury (Chen et al 2002). Animal studies have quantified the effects of graded hypotension on cerebral blood flow, blood volume and transit time; (Ferrari et al 1992) and with continuous time domain analysis cerebral oximetry have allowed assessment of autoregulation, which could be used as a means of optimizing cerebral perfusion pressure in patients with acute brain injury (Brady et al 2007). Most recently mapping of cortical blood flow using grids of NIRS sensors has identified cortical areas responsible for speech and language development.

Future advances in hardware and software related to MRI, spectroscopy and diffusion tensor imaging will likely allow such technologies to contribute more by delineating the site(s) and extent of neuronal injury, (Perlman 2011) and aid in evaluation and management strategies able to mitigate the long term effects of perinatal brain injury.

Multisystem involvement: The consequences of fetal hypoxic ischemic stress extend beyond the brain. The lungs of asphyxiated infants can be injured directly by hypoxia, as a consequence of inhaled meconium, secondary to left ventricular failure, or compromised from pulmonary hypertension. (Lapointe \& Barrington 2011) The end result is impaired gas exchange and the need for assisted ventilation to maintain adequate oxygenation and carbon dioxide exchange. The risks of brain injury increase where such effects are superimposed on the poorly compliant lungs of a preterm infant; pneumothorax (air leak into the pleural space causing lung compression) is less common with modern ventilation techniques, but when it occurs, major disturbances in cerebral perfusion pressure result that increase the risk of serious brain haemorrhage.

Direct damage is caused to the myocardium of the heart; this and the consequences of compensatory mechanisms to preserve cerebral perfusion that divert blood flow away from other organs result in a recognizable clinical and laboratory picture; as summarized in the Table by Phelan in a recent study with definitions based on Hankins et al. (Phelan et al 2011; Hankins et al 2002) The cardiac effects of myocardial ischemia compromise conduction and mechanical (contractile) efficiency, and often require heart function to be supported with inotropic agents such as dopamine to maintain adequate circulation. Functional and conduction abnormalities are evident on cardiac echo and electrocardiogram, and elevated cardiac enzymes reflect heart muscle damage. The other multisystem effects are principally on renal, hepatic, and bone marrow function. Renal injury is the best systemic marker of potential brain injury; especially when reduced urine output (oliguria = urine output $<1 \mathrm{ml} / \mathrm{kg} / \mathrm{h}$ ) is associated with an abnormal neurological examination. (Perlman 2011) Absent or significantly reduced urine output in the 24 hours following hypoxic ischaemic injury is common, is often accompanied by haematuria, and reflects renal tubular damage. Blood urea and serum creatinine concentrations rise progressively and peak in the days following injury. Inappropriate secretion of antidiuretc hormone occurs, which causes fluid retention, which causes serum sodium levels to fall (hyponatraemia). The effect on the bone marrow and haemopoesis is reflected by an increase in the release of nucleated red blood cells which peaks at 6-8 hours after brain injury and falls to normal by $36-72$ hours. Platelet numbers fall (thrombocytopaenia), sometimes by 12 hours, the nadir occurring at 2-3 days. (Beyene et al 2009) Thrombocytopaenia can be severe enough to cause or potentiate bleeding including within the brain. Serum calcium levels often fall; liver enzymes reflecting hepatic 
cellular damage increase, and blood glucose concentration can fluctuate, with low levels (hypoglycaemia) being most common.

Hypoglycaemia has recognized neurologic consequences, (Alkalay et al 2005a; Burns et al 2008; Karimzadeh et al 2011) especially when low glucose concentrations cause or accompany seizures. E.g. motor and/or psychodevelopmental delay, microcephaly (Alkalay et al 2005b), spastic quadriplegia and hemiplegia, seizures and visual impairment (Burns et al 2008). Imaging studies document the presence of oedema and hyperechogenic areas in the acute phase (Alkalay et al 2005b), and later, a high incidence of white matter injury, including a proportion with global damage (Burns et al 2008). Focal damage evident unilaterally or bilaterally has also been seen in a range of locations, including in the parietal and occipital lobes, and cortex, and in one case in the brain stem (Alkalay et al 2005a; Burns et al 2008; Barkovich et al 1998). Hyperglycaemia also has the potential to cause or aggravate brain damage, principally because of the hyperosmolar state that ensues (Efron et al 2003; Volpe 2001a).

\begin{tabular}{|l|l|}
\hline Organ Involved & Clinical / Laboratory Features \\
\hline \multirow{3}{*}{ Heart } & $\begin{array}{l}\text { Cardiac dysfunction requiring dopamine to support circulation } \\
\text { Elevated creatine phosphokinase (CPK) } \\
\text { Echocardiogram/electrocardiogram abnormalities }\end{array}$ \\
\hline \multirow{2}{*}{ Kidneys } & $\begin{array}{l}\text { Absent or reduced urine output } \\
\text { Elevated creatinine }\end{array}$ \\
\hline Liver & $\begin{array}{l}\text { Global hepatic dysfunction with elevated enzymes } \\
\bullet \quad \text { serum glutamic-oxaloacetic transaminase (SGOT) }\end{array}$ \\
\hline Lung & $\begin{array}{l}\text { Abnormal respiratory drive and lung compliance requiring assisted } \\
\text { ventilation }\end{array}$ \\
\hline Intestines & $\begin{array}{l}\text { Feeding intolerance } \\
\text { Abnormal peristalsis }\end{array}$ \\
\hline Bone Marrow & $\begin{array}{l}\text { Release of primitive cell lines (nucleated red blood cells) } \\
\text { Depression of total platelet numbers }\end{array}$ \\
\hline
\end{tabular}

Table 3. Multisystem Involvement in the first days of life following fetal hypoxic ischaemic injury (Modified from Phelan et al 2011)

Prevention of hypoxic ischaemic brain injury centres on labour and delivery but relies on attention to multiple factors during many phases of pregnancy. Good antenatal care is fundamental to optimal maternal and fetal health. Prior medical history, particularly pregnancy outcome, needs to be considered; then regular maternal examination and investigation follow to confirm gestational age, ensure appropriate fetal growth, and plan for appropriate timing and means of delivery; supervision during labour provides the means for anticipation, monitoring and intervention that underlie good obstetric care and underpin optimal fetal outcome including the lowest chance of brain injury occurring for any reason.

In the context of intrapartum situations that put the fetus at risk of neurological sequelae, guidelines exist for most situations to anticipate, prevent, or minimize morbidity. In many 
situations, and with fetal hypoxia in particular, the physiological effects on the fetus generate detectable changes in the fetal heart rate. The fetal myocardium and brain are sensitive to reduction in oxygen tension, and become all the more so as elevation of carbon dioxide occurs and significant acidosis develops. Importantly, the changes in heart rate and cardiac function that result occur prior to brain metabolism being affected sufficiently for damage to begin. A non-reassuring pattern or individual changes in fetal heart rate reflecting alteration in cardiac function occur, most often in relation to uterine contractions which even during uncomplicated labour place an element of stress of the fetus. This is because the haemodynamics of placental blood flow alter as the tone of the uterus increases; blood flow through the umbilical cord on which the fetus depends is also vulnerable during contractions. During the later stages of labour, when the fetus is moving down the birth canal, cord compression, entrapment or prolapse through the cervix can occur. These situations compromise blood flow to varying degrees; in addition to oxygen delivery to the fetus being affected, perfusion and removal of carbon dioxide and acids from the fetus can become impaired. Sometimes a 'sentinel event' is detected with an abrupt and sustained drop in fetal heart rate. Such events occur in association with events such as uterine rupture, placental abruption, cord occlusion/prolapse, maternal collapse, or intra-partum haemorrhage. It is the association of such events with brain injury (Okereafor et al 2008) and the physiologic perturbations in fetal oxygenation and haemodynamics that they reflect that provide the rationale for fetal heart rate measurement and electronic fetal monitoring (EFM) (Macones et al 2008; Liston et al 2007; Am Col Obs Gyn 2005; Royal College Obs Gyn 2005). The purpose of EFM is to provide recognition of 'non-reassuring' patterns or frank abnormalities in heart rate that leads to prompt obstetric assessment, intervention(s) required to relieve compromise to the fetal circulation, or expedited instrumental delivery or emergency caesarean section.

Guidelines for electronic fetal monitoring have been generated in most jurisdictions (Macones et al 2008; Liston et al 2007; Am Col Obs Gyn 2005; Royal College Obs Gyn 2005). However, EFM became part of clinical practice following retrospective studies comparing its use to historical controls where auscultation was performed. And while case-control studies have shown correlation of EFM abnormalities with umbilical artery base excess; only 1 of 13 randomized controlled trials showed a significant decrease in perinatal mortality comparing EFM with auscultation; and meta-analysis found an increased incidence of caesarean delivery and decreased neonatal seizures but no effect on the incidence of cerebral palsy or perinatal death. (Graham et al 2008)

Placental pathology: the placenta is one of the least well understood organs in the human body, yet it is integral to fetal perfusion, gas exchange (oxygenation and carbon dioxide excretion), and nutrition, and protection of the fetus from infection. Many common maternal conditions interfere with placental function and fetal oxygenation, including hypertension, diabetes, and sickle cell anaemia. The fetus is at particular risk of brain injury in conditions where the disturbance of placental gas exchange and fetal perfusion becomes acute and severe; examples include pre-eclamptic toxaemia (which, if unchecked, also requires delivery of the fetus, regardless of the gestation achieved, in order to restore maternal blood pressure and coagulation status), and haemorrhage from placenta praevia or abruption where bleeding occurs between the placenta and the uterine wall. In one study aimed at establishing the antecedent factors and patterns of brain injury in preterm infants with HIE, 
placental abruption was the commonest identifiable event (Logitharajah et al 2009). Acute maternal infection and transplacental passage of inflammatory cytokines expose the fetal brain to direct and indirect damage, and the associated risks of preterm delivery where premature rupture of membranes and preterm labour occurs. Less acute situations predominantly stem from progressive failure of the placenta to function and provide nutrition and gas exchange. Growth retardation occurs with progressive slowing of fetal somatic and brain growth (intrauterine growth retardation) and increasing risk of acute placental insufficiency leading to fetal distress, again with the likelihood of hypoxia and ischemia as the predominant mechanism of brain injury. The umbilical cord, which is the conduit for blood flow and gas exchange between the placenta and fetus, is also vulnerable; compression, prolapse, occlusion, entrapment and tearing occur, each of which has recognized adverse consequences for fetal oxygenation and cerebral blood flow. Partial and prolonged and acute near total episodes of hypoxic ischaemic stress occur in consequence. Overall the incidence of interruption of adequate placental blood flow during labour is approximately 3 of every 1000 term deliveries (Perlman 2011)

Instrumental delivery: A number of situations require delivery assisted by forceps or vacuum extraction. In many instances concern over a non-reassuring pattern in the fetal heart rate or other evidence suggests fetal distress has developed, or delivery has been delayed sufficiently for the mother or fetus to be deemed at risk. The principal of forceps delivery is to place the blades of the instrument on either side of the fetal head so as to contain it within the forceps. Gentle traction is then applied to the handles of the forceps in order to dilate the cervix and allow the fetal head to progress down the birth canal. Forceps are not intended to pull the fetus through the cervix. With mis-application or undue traction applied head trauma can occur - this can result in facial injury including facial palsy, skull fracture and intracranial bleeding. Vacuum extraction involves attaching a suction cup to the baby's head and then gently applying traction to help ease the baby down the birth canal. Although permanent sequelae can result with either motor or cognitive damage, generally instrumental delivery does not result in permanent brain injury except under more extreme circumstances. This is because there are strict guidelines related to both the application of forceps and the use of vacuum extraction, all of which are intended to optimize delivery and avoid the risk of head trauma and associated brain injury. The principal risks with forceps are application when the fetal head is high in the birth canal, attempts to rotate the fetal head, or use of excessive force; and with use of the vacuum extractor application when the fetus is not sufficiently advanced down the birth canal, or for periods that are overly long or repetitive.

Infants adversely affected often show a degree of neurological depression at birth, and some have evidence of skull fractures; there can be associated underlying cortical damage (Ferriero 2004), and/or subdural or intracranial bleeding. Cerebellar injury is also described (Limperopoulos et al 2009) A small proportion of these brain injured infants then go on to develop signs of encephalopathy in the newborn period, but most recover. Occasionally the mechanical problems related to the volume of intracranial bleeding require surgical drainage. In the premature infant if bleeding occurs that extends into the intraventricular compartment this can result in post-haemorrhagic hydrocephalus.

Breech delivery. The key issues to avoid brain injury in infants presenting by the breech (bottom first - or with the part normally covered by the britches presenting) are assistance 
during delivery to protect the after coming head and the attendance of staff to effectively resuscitate the infant, who in many instances is born prematurely and after a degree of hypoxic stress. The central problem that predisposes the infant presenting by the breech to brain injury is that in the fetus the dimensions of the bottom are smaller than those of the head. Hence, after the body of the fetus has passed through the cervix the degree of dilatation is insufficient for the after coming head to avoid entrapment. As a result delivery is delayed and there is a risk that hypoxic ischemic brain damage will occur.

The related problem is that when the head is released by the partially dilated cervix an abrupt and significant change in intracranial pressure occurs that is associated with a comparably large and sudden alteration in cerebral blood volume. In infants who are premature in particular this change in pressure and blood volume results in fluctuations in cerebral blood flow that are sufficiently extreme for brain ischemia to be followed by hyperperfusion that often results in brain haemorrhage. Superimposed on the period of hypoxia and ischemia caused during head entrapment this fluctuation in blood volume is often sufficient to cause bleeding into the brain and/or significant brain injury.

Preventive measures include recognition of breech presentation, and appropriate planning to ensure optimal delivery and resuscitation. This may involve operative delivery by caesarean section or protection of the after coming head with forceps during delivery, and the availability of trained staff to optimally resuscitate a potentially asphyxiated and possibly premature infant. In addition, planning is required to ensure safe transport of the mother to an appropriate level of care prior to delivery whenever possible, or the availability of local staff and/or transport team personnel to resuscitate, care for, and where necessary relocate the newborn infant to a facility capable of providing the care he/she requires after birth.

Large for gestational age infants are those weighing more than the $90^{\text {th }}$ centile for their age. Such infants are often born to mothers who develop gestational diabetes. Because they are large these infants may experience difficult or delayed delivery with the inherent associated risks of hypoxic stress. Generally pregnancies compromised by gestational diabetes and accelerated fetal growth are electively ended by induction of labour prior to term. This reduces the risk of still birth and fetal morbidity from a number of causes. However, the principal risk that large gestational age infants face relates to their disordered glucose homeostasis that puts them at risk of hypoglycemia in the newborn period. This requires careful monitoring of blood glucose and provision of adequate substrate (usually in the form of frequent oral or nasogastric tube feeds, or a constant infusion of intravenous glucose) sufficient to maintain normoglycaemia. Where seizures occur due to hypoglycemia there is a recognized associated morbidity with the brain being vulnerable to injury and the risk of abnormal neurodevelopmental outcome. In addition seriously affected infants may also have a problems related to cardiac function and the maintenance of an adequate circulation due to a pericardial effusion that compromises cardiac output, and hence potentially results in impaired cerebral blood flow capable of resulting in brain injury.

Post mature infants (those born after 42 weeks of gestation) have a number of risks of brain injury related to their post maturity; these are mainly still birth or fetal distress due to placental failure or obstetric complications during delivery. Rare associations of post maturity with of brain anomaly include anencephaly, and bird-headed dwarfism. 
Multiple pregnancy. The incidence of twins is $11-13$ per 1000 pregnancies with a predisposition amongst African Americans. Triplet and higher-order multiple births are increasing due to IVF. Risks of brain damage exist because of a higher incidence of premature delivery and low birth weight, the risks associated with being born second (or later) and experiencing hypoxia in consequence, and a higher incidence of cord accidents than in singleton births. Congenital brain anomalies occur including anencephaly and holoprosencephaly. Vascular shunts between twins and the death of one twin can cause a variety of problems; resulting in polycythemia, stroke from emboli, and haemorrhage that can cause brain damage.

Haemorrhage. Major causes of bleeding include placental abruption (separation from the uterine wall), placenta praevia, maternal trauma, damage to the umbilical cord, and intraventricular haemorrhage. Where haemorrhage involves a significant volume of blood loss the fetus loses the ability to maintain adequate levels of oxygen delivery and tissue perfusion. While acidosis and hypoxia result brain damage occurs principally because mean blood pressure can no longer be maintained, cerebral blood flow falls and hypoxic ischemic injury follows. In the preterm infant fluctuations in cerebral perfusion during the evolution and management of haemorrhage are often damaging in their own right. Where a maternal cause exists, interventions to resuscitate the mother and intervene to address the underlying cause of the haemorrhage benefit the infant, provided they are instituted promptly and either restore fetal oxygen delivery and perfusion, or deliver the infant allowing extrauterine resuscitation. Infants born following a haemorrhagic event need immediate assessment at birth of the adequacy of their circulation as part of their resuscitation. Such infants not infrequently require prompt intravenous fluid replacement to restore their blood volume to adequate levels for normal perfusion and oxygen delivery to occur. Delay in delivery of this component of resuscitation can compound the degree of existing hypoxic ischemic brain injury. Any pale and neurologically depressed infant needs an assessment of the adequacy of blood pressure and circulation in addition to support of respiration, oxygenation and cardiac function.

Hydrops fetalis is a condition where fluid accumulates in the fetus to an extensive degree. The majority of cases used to relate to Rhesus disease. Human parvovirus B19 infection should be considered in any case of nonimmune hydrops; (De Haan et al 2006) diagnosis is mainly through serology and polymerase chain reaction. Surveillance requires sequential ultrasound and Doppler screening for signs of fetal anaemia, heart failure and hydrops. Intrauterine transfusion in selected cases can be life saving. Cardiac arrhythmia due to supra ventricular tachycardia (SVT) can be severe enough in a fetus to cause hydrops, and is associated with significant morbidity and mortality. Several reports link SVT with neurological morbidity, including periventricular leukomalacia (PVL) and spastic diplegia (Oudijk et al 2004). SVT severe enough to compromise cardiac function and cause hydrops reduces brain blood flow sufficiently over time for ischemia and hypoxia to cause brain damage. SVT is the most common cause of non-immune hydrops, but it is also the most amenable to treatment (Porat et al 2003). Fetal heart rate monitoring is used to diagnose and follow fetal arrhythmias. Diagnosis of hydrops is made by ultrasound when generalized skin thickening of greater than $5 \mathrm{~mm}$ is present associated with two of the following criteria: ascites (fluid in the abdominal cavity), pleural effusion, pericardial effusion or placental enlargement (Oudijk et al 2004). 
If the fetus is mature enough, delivery and post natal treatment is then possible. But if the risk from complications of prematurity is too high for safe delivery, therapeutic intervention with medication can preserve fetal well-being, as treatment with anti-arrhythmic agents ablates the arrhythmia and improves cardiac function. There is evidence that the adverse affects of SVT can be tolerated by a fetus for a period of time which makes it probable that adequate blood flow to the fetal brain continues initially. But unrecognised and untreated, worsening cardiac dysfunction leads to hydrops and compromise of brain blood flow. For this reason early diagnosis and interventional management to relieve the adverse effects of SVT on the brain are central to ensuring good neurological outcome, particularly in a premature infant with an immature brain (Oudijk et al 2004; Porat et al 2003).

In-vitro fertilization (IVF): Population based studies in Australia, Sweden and the USA document that while most children born after IVF are healthy, there are increased rates of multiple pregnancy, low birth weight, genetic anomalies, and disability (Hansen et al 2002; Schieve et al 2002; Stromberg et al 2002). Infants conceived using IVF are more likely than controls to develop neurological disability, impairment or handicap, and especially cerebral palsy; this effect is attributed largely but not solely to the high frequency of twins born, and to low birth weight and low gestational age, but an effect due to the IVF procedure per se cannot be excluded (Stromberg et al 2002). The risk of major birth defects may be as much as twice as high as for naturally conceived infants (Hansen et al 2002) and the incidence of low birth weight is higher for singletons as well as twins. (Schieve et al 2002)

Stroke: Strokes can occur in a fetus between 14 weeks of gestation and delivery, and result in cerebral palsy, mental retardation and epilepsy. In a review (Ozduman et al 2004) 78\% of cases of fetal stroke with a reported outcome resulted in either death or adverse neurodevelopmental outcome. The principal causes are ischaemic, thrombotic or haemorrhagic injuries occurring in utero. Most fetal strokes are of unclear origin, but associated maternal conditions recognized to underlie some cases include platelet abnormalities, placental pathologies, medication (warfarin and antiepileptic medication associated with a decrease in vitamin $\mathrm{K}$ dependent coagulation factors), trauma, twin to twin transfusion, and Parvovirus B19 infection; fetal factors include cytomegalovirus infection and protein C deficiency (Ozduman et al 2004; De Haan et al 2006). Diagnosis in utero may be made on routine ultrasound. MRI is the optimal imaging modality.

\section{Cerebral Palsy}

Cerebral Palsy $(\mathrm{CP})$ is the term used for a group of non-progressive disorders of movement and posture caused by abnormal development of, or damage to, motor control centers of the brain. CP is defined as a static neuromuscular disorder characterized by an abnormal control of movement or posture appearing early in life that is not the result of a recognizable progressive disease. (Nelson \& Ellenberg 1981) CP has a prevalence of approximately 2 per 1,000 live births and is caused by a variety of congenital and acquired events before, during, or after birth. (Phelan et al 2011) CP has been investigated extensively for epidemiologic risk factors with research dating back to the 1970s. (O'Callaghan) A number of key factors have been well established to be associated with $\mathrm{CP}$ from population-wide databases, and with near complete ascertainment and a low likelihood of bias. These include preterm birth, low birth weight, infection in pregnancy, and twin births. (O'Callaghan et al 2011) However, a large proportion of cases have no identifiable cause, while approximately $10 \%$ are 
estimated to be attributable to asphyxia. (Yudkin et al 1995) Phelan identified the association of a sudden and sustained deterioration in fetal heart rate with the criteria developed by the task force on neonatal encephalopathy and cerebral palsy for intrapartum asphyxial injury in cases where a diagnosis of $\mathrm{CP}$ was subsequently made. In a cohort of 7242 children who developed $\mathrm{CP}, 31.3 \%$ had had one or more of six defined adverse intrapartum events (placental abruption, uterine rupture during labour, fetal distress, birth trauma, umbilical cord prolapse, and mild-severe birth asphyxia). (Gilbert et al 2011) Prematurity has the greatest impact on the future development of $\mathrm{CP}$, hence the higher incidence of $\mathrm{CP}$ in such infants. (Gilbert et al 2011) However, birth asphyxia, birth defects and adverse labour events contribute significantly as well, suggesting that in preterm infants CP is most likely multifactorial (Sukhov et al 2011). There is also data supporting an association between $\mathrm{CP}$ and maternal infection late in gestation, intrauterine growth restriction, early gestational age, multiple birth, family members with cerebral palsy, breech position, smoking and drug use, low Apgar scores, male sex, caesarean delivery, and previous miscarriages. (O'Callaghan et al 2011)

By some, "intrauterine infection/inflammation is considered to be the leading identifiable risk factor for cerebral palsy" (Bashiri et al 2006) as it so commonly causes neonatal complications, including preterm delivery. And while prematurity is a major causal factor in $\mathrm{CP}$, the odds of brain injury occurring become much greater in the presence of maternal fever, the effects of inflammation, or proven infection than when the only risk factor is prematurity. (Gotsch et al 2007; Bashiri et al 2006; Grether \& Nelson 1997)

Criteria (with qualifying definitions) have been developed to define an acute intrapartum hypoxic event sufficient to cause cerebral palsy by the Task Force on Neonatal Encephalopathy and Cerebral Palsy (American College of Obstetricians and Gynecologists 2003). The key criteria are summarized in Table 4.

\begin{tabular}{|c|c|}
\hline $\begin{array}{l}\text { Essential criteria } \\
\text { (must meet all four) }\end{array}$ & $\begin{array}{l}\text { - } \quad \text { Metabolic acidosis (fetal umbilical cord arterial blood) } \\
\text { - } \quad \text { Encephalopathic state evident in newborn period. } \\
\text { - } \quad \text { quidence of cerebral palsy at follow up (spastic } \\
\text { - } \quad \text { Exclusion of other causal mechanisms for CP }\end{array}$ \\
\hline $\begin{array}{l}\text { Criteria that } \\
\text { together suggest } \\
\text { intrapartum timing, } \\
\text { but support rather } \\
\text { than confirm an } \\
\text { asphyxial cause }\end{array}$ & $\begin{array}{ll}\text { - } & \text { Sentinel event (immediately before or during labour) } \\
\text { - } & \text { Bradycardia (sudden or prolonged), or absent fetal heart rate } \\
\text { - } & \text { (with persistent, late, or variable decelerations) } \\
\text { - } & \text { Multiorgan involvement in the newborn period } \\
\text { - } & \text { Early brain imaging showing nonfocal abnormalities }\end{array}$ \\
\hline
\end{tabular}

Table 4. Criteria used to link an acute intrapartum hypoxic event with cerebral palsy

The abnormalities of muscle control that define CP are often accompanied by other neurological and physical abnormalities, and the movement impairments that occur reflect the area of brain damaged. Muscle function is variously compromised: they may be contracted and tight (spastic); exhibit involuntary writhing movements (athetosis); have difficulty with voluntary movement (dyskinesia); and/or exhibit lack of balance and coordination with unsteady movements (ataxia). Monoplegia describes involvement of 
muscles in one limb; diplegia involvement of both arms or both legs; hemiplegia involvement of both limbs on one side of the body; and quadriplegia involvement of all four limbs. CP is categorized first by the type of movement/postural disturbance present, then by a description of which limbs are affected, and finally by the severity of motor impairment. These three-part descriptions are helpful in providing a general picture, but cannot give a complete description of any one person with $\mathrm{CP}$. The four major classifications used to describe $\mathrm{CP}$ are:

- Spastic

- Athetoid/Dyskinetic

- Ataxic

- Mixed

\section{Investigations relevant to causation of brain injury}

Assessment at birth allows the immediate needs of the newborn infant to be provided in terms of the resuscitation required to ensure transition from intrauterine to extra uterine life. This is a key element in mitigating any residual effects of intrapartum events that have damaged the brain or compromised function. It is recognized that the immediate availability of skilled personnel able to do this is an important factor in reducing morbidity, especially amongst sick and premature newborns, and one of the central responsibilities of those providing for their care. In this regard the priorities for resuscitation include establishing effective respiration and gas exchange and cardiac output and perfusion, ensuring temperature stability to avoid hypothermia, which increases oxygen requirements, and addressing any metabolic abnormalities or potential instability. Risks related to any other intrapartum causes or aggravating factors in the context of brain function or existing injury can also be addressed; examples include the presence or potential for infection to require investigation and treatment with prophylactic antibiotics.

Once the infant is adequately resuscitated, assessment also allows the gestational age of the newborn to be assessed, physical growth parameters (height, weight and head circumference) to be measured and plotted against standard values, general physical examination to be performed to identify any systemic problems, dysmorphic features, or congenital anomalies, and full examination of general status of the infant to occur. From the standpoint of actual or potentially evolving brain injury, the neurological system is examined in detail and the status of the infant documented as a baseline, and as a means of planning the next phase of care and appropriate investigations and consultation, and beginning the process of considering the ultimate prognosis. Generally an infant born with signs of neurological depression, associated with acidosis and low Apgar scores, is considered likely to have experienced hypoxia and ischemia during labour; this becomes more and more probable where signs of neurological depression and brain dysfunction (encephalopathy) evolve in the hours or days that follow birth.

Umbilical cord blood gas analysis: Levels of fetal oxygenation and acid base status at birth can be assessed from cord blood gas measurements taken at birth. Values differ between samples taken from the vein which delivers oxygenated blood to the fetus from the placenta and one of the two cord arterial vessels that return blood from the fetus to the placenta. Recent significant hypoxic ischemic stress manifests with low oxygen levels and elevated 
$\mathrm{PCO}_{2}$, and low $\mathrm{pH}$, low bicarbonate and high base deficit levels (elevated acidity). Low $\mathrm{pH}$ values and high base deficit values in the umbilical arterial sample correlate with an increased probability of permanent neurological sequelae following fetal exposure to hypoxia and ischemia. The criteria to define an acute intrapartum event as sufficient to cause cerebral palsy include a $\mathrm{pH}<7.00$ and base deficit of $>12 \mathrm{mmol} / \mathrm{L}$. (Phelan et al 2011) The threshold for moderate or severe newborn complications associated with metabolic acidosis is an umbilical artery base deficit of $>12 \mathrm{mmol} / \mathrm{L}$. (Low et al 1997) Comparison of results from reported studies demonstrates a progression of newborn complications with increasing severity of metabolic acidosis. The mean value for arterial $\mathrm{pH}$ is $7.26+/-007$ (Helwig et al 1996), and a $\mathrm{pH}$ of $<6.8$ equates with the probability of neonatal death or major neurologic dysfunction (Goodwin et al 1992)

The range of normal for cord blood gas values in term infants have been reported by Liston (Liston et al 2007). The values (mean +/- SD) for umbilical artery samples are: $\mathrm{pH}=7.27+/-$ 0.069; $\mathrm{PCO}_{2}=50.3+/-11.1 \mathrm{mmHg} ; \mathrm{HCO}_{3}=22.0+/-3.6 \mathrm{mEq} / \mathrm{L} ;$ and Base deficit $=-2.7+/-$ $2.8 \mathrm{mEq} / \mathrm{L}$. For umbilical vein samples, values are: $\mathrm{pH}=7.34+/-0.063 ; \mathrm{PCO}_{2}=40.7+/-7.9$ $\mathrm{mmHg} ; \mathrm{HCO}_{3}=21.4+/-2.5 \mathrm{mEq} / \mathrm{L}$; and Base deficit = -2.4 +/- $2.3 \mathrm{mEq} / \mathrm{L}$.

Acidosis occurs as a consequence of cellular hypoxia (inadequate oxygenation) and tissue ischemia (inadequate blood flow). Metabolic and respiratory forms are recognized. The test used to measure tissue acidity is a blood gas where $\mathrm{pH}$ is the principal unit of measurement - $\mathrm{pH}$ values are on a logarithmic scale so that small differences represent a major change in the level of acidosis. Normal cell function only occurs within a narrow range of $\mathrm{pH}$, beyond which the ability of cells to maintain normal oxygen and carbon dioxide exchange and metabolic and mechanical function is progressively compromised as the degree of acidosis increases. The association between acidosis and development of permanent brain injury from hypoxic ischemic injury usually occurs in infants who are acidotic and also neurologically abnormal at birth, and then develop clear signs of brain dysfunction (HIE) in the newborn period.

Apgar score. Named for Virginia Apgar, this is an objective index used to evaluate the condition of a newborn infant based on a rating of 0,1 or 2 for each of the five components: colour, heart rate, response to stimulation of the sole of the foot, muscle tone, and respiration. Scores are determined by observing/examining the newborn infant at 1, 5 and 10 minutes of age. 10 is the maximum (perfect) score. Babies that have low Apgar scores are at increased risk for $\mathrm{CP}$, particularly when low scores persist in spite of resuscitation being implemented. Care with interpretation is required where an infant is premature due to an associated degree of physical immaturity, and also when scores are estimated after the fact as often occurs when active resuscitation is required.

Ultrasound (US) studies and neuroradiological scans (Computerized Tomography (CT) and/or Magnetic resonance imaging (MRI): Ultrasound provided the initial method for imaging brain structure and is still clinically attractive because of the ability to study sick infants in the nursery environment. The development of CT and advent of broadly available computer generated images of the brain greatly advanced clinical diagnosis and knowledge related to brain development and injury. The outstanding contrast resolution of MRI, superimposed on the ability to image in any plane, now allows the identification of even subtle brain malformations. (Francis et al 2006) US, CT, and MRI scans are today usually 
done at defined intervals after birth in order to evaluate the timing and evolution of brain injury. Pathology that can be identified includes structural developmental abnormalities, oedema (brain swelling), haemorrhage, early ischemic damage, localization of injury to cortical tissue or deep brain structures (basal ganglia and thalami), onset and evolution of scarring, onset and progression of hydrocephalus or microcephaly. Cerebral oedema following hypoxic ischaemic brain injury usually subsides in 48-72 hours, allowing recovery of brain stem function; (Perlman \& Shah 2011) and intrapartum or late antepartum hypoxic ischaemic changes can be distinguished from structural brain damage due to congenital or acquired causes that occurred well prior to birth.

Advanced methods of neuroimaging are the subject of recent reviews; (Glenn \& Barkovich 2006; Mathur et al 2010; Counsell et al 2010; Huang \& Castillo 2008) MRI, magnetic resonance spectroscopy (MRS), and diffusion-weighted MRI have shown the patterns of brain injury that evolve after hypoxic ischaemic insults, that such patterns depend on the severity of the insult and the age at which it occurs, and that brain injury evolves over days, if not weeks. (Ferriero 2004) The anatomical regions of the brain affected by hypoxic ischemic injury define whether the insult occurred acutely and was near total in nature or occurred over a more prolonged period and was partial in degree. Deep brain structures have a high metabolic rate and hence are injured in acute profound hypoxia as significant ischemia develops before compensatory changes in cerebral perfusion can occur. In contrast, in partial and prolonged hypoxia, acidosis evolves that leads to preferential perfusion of deep brain structures; but ultimately, perfusion of the cerebral cortex is compromised and this area of the brain suffers hypoxic ischemic damage.

Fetal and post-natal MR imaging have redefined the diagnosis of congenital and acquired brain injury developing in utero and during the intra-partum period (Glenn \& Barkovich 2006). Fetal MR imaging is a technique that complements prenatal sonography as it has higher contrast resolution and allows direct visualization of the fetal brain, and hence more readily identifies both cerebral malformations and destructive lesions; including agenesis of the corpus callosum, cerebellar dysplasia, germinal matrix haemorrhage, intraventricular haemorrhage, multicystic encephalomalacia, periventricular leukomalacia, periventricular nodular heterotopias, poroncephaly, and sulcation anomalies (Filey et al 1991; Aubry et al 2003).

The most common abnormality observed is enlargement of the ventricles (ventriculomegaly), which may result from multiple developmental, obstructive and destructive causes; in the majority of cases there are associated anomalies within or beyond the central nervous system, which significantly increase the probability of the affected infant having developmental delay. Destructive lesions are characterized by periventricular hyperintensity, focal defects in the germinal matrix, or areas of abnormal signal intensity in the developing white matter. Haemorrhage is usually associated with hypointense areas, although signal intensity does vary depending on the stage of evolution.

For post-natal studies diffusion-weighted MR imaging and proton MR spectroscopy are the most sensitive modalities for diagnosis in the early hours following injury and recent publications describe the major findings observed (Huang \& Castillo 2008).

Electroencephalogram (EEG) recording monitors the electrical activity of the brain. Seizure activity occurring in the brain but not visible clinically may be detected by EEG. Patterns of 
brain waves are obtained that allow the location and relative severity of various brain pathologies to be identified. Patterns of depression of cortical brain activity on EEG have been defined (Table 2) associated with varying stages and severity of hypoxic ischemic encephalopathy (Sarnat and Sarnat 1976). Serial measurements are helpful to document the evolution and recovery of abnormal brain function and the effect of therapy.

Blood counts: The presence of abnormal findings in the white blood cell (WBC) count are strongly indicative (although not diagnostic) of the presence of bacterial infection due to septicaemia (bacteria multiplying in the blood stream). (Gerdes 2004) Very low counts indicate the inability of an infant to mount an effective immune response; elevated numbers of total WBC cells, a high proportion of neutrophils (granulocytes), and elevated numbers of primitive (band) cells indicate that stimulation of the bone marrow by inflammatory cytokines has occurred, and hence such changes evolve over time. Elevation of the band cell count is the earliest change seen in the peripheral blood count in response to an inflammatory stimulus, which is the most common cause of increased release of primitive (band) cells, although hypoxia can also result in an increase in band cell number.

Measures of haemoglobin concentration or the volume of red blood cells in the circulation are used to identify anaemia and polycythemia where too few or too many red cells are circulating respectively. Both circumstances compromise oxygen delivery; anaemia by limiting the amount of oxygen that can be transported, and polycythemia by reducing the ease with which blood flows, which also increases the risk of blood vessel occlusion (thrombosis) and is one of the mechanisms underlying stroke. Also, by following serial measurements from birth, situations can be identified where bleeding occurred while the fetus was in utero. After significant blood loss, the volume of the blood in the circulation is reduced, but the haemoglobin concentration remains the same. As physiological compensation following haemorrhage occurs, fluid is drawn into the circulation to restore blood volume and, as a consequence, haemoglobin concentration and the number of red cells per unit of volume (hematocrit) fall.

Blood chemistry: The full range of biochemical abnormalities associated with brain injury is beyond the scope of this chapter. Congenital metabolic abnormalities constitute a small but complex group of conditions that require expert assessment, investigation and management. Blood glucose, and serum calcium, and electrolyte measurements, in parallel with blood gas analysis of $\mathrm{pH}$, oxygen and carbon dioxide tension, bicarbonate and base deficit, are the mainstays of clinical monitoring in brain injured infants, particularly when multisystem involvement complicates the course of neonatal encephalopathy. Fetal measurement of some parameters is feasible; scalp blood sampling in particular has relevance in assessing the evolution of hypoxia and acidosis during the later stages of labour via blood gas measurement or lactate analysis, once the membranes have ruptured and the fetal head has descended into the birth canal. Lactate is a metabolite in aerobic metabolism and reflects tissue hypoxia. (Wiberg-Itzel et al 2008)

\section{Prevention of fetal brain injury}

Prevention of fetal brain damage requires knowledge of the aetiologies underlying injury, awareness of the availability of preventive measures, and the opportunity to employ them to address the underlying cause. In addition, situations that may aggravate existing or 
evolving brain injury need to be recognized and care provided that is capable of improving outcome. Treatment of the effects of fetal brain injury often begins during the newborn period and some entities contribute to better outcome. However, the many therapies that have to continue during childhood to support infants born with brain damage and those that are entailed in providing for their care in adult life are beyond the scope of this chapter.

Maternal health and diet, parental age, and mode of conception are all relevant. (Hagberg \& Mallard 2000) The risk of fetal brain injury is decreased where mothers maintain a good diet, add appropriate folic acid and iron supplements, and avoid smoking, the detrimental effects of alcohol, and exposure to TORCH infections. There are benefits to becoming a mother earlier rather than later in life and from lifestyles that promote physical health and mental wellness. In vitro-fertilization is associated with an increased risk of multiple pregnancy, preterm delivery and some specific structural defects. Good antenatal care is central to optimizing the fetal environment, detection of entities that require intervention or forward planning, and allowing pregnancy to progress to term. The fetal brain probably benefits most from prevention of avoidable preterm delivery, and therapy such as antenatal steroid use to mature the fetal lung (Hagberg \& Mallard 2000) when prematurity is inevitable. Post maturity with the inherent risks of placental failure and increased fetal morbidity must be avoided, especially where at risk situations exist such as gestational diabetes. Mothers who have had previous caesarean section require special planning and supervision to avoid uterine complications that can jeopardize fetal wellbeing.

Monitoring during pregnancy should screen for and detect major genetic anomalies, as termination of pregnancy is a care option for limiting the incidence of brain injury when a fetus is known to have a major anomaly. Confirmation of gestational age by monitoring fundal height and using confirmatory ultrasound also reduces the risk of prematurity. And allows monitoring of fetal growth parameters to anticipate and manage intrauterine growth retardation, and identify placental anomalies that carry a risk of increased morbidity. Surveillance for a broad range of maternal illnesses is also possible with preventive entities available to optimize fetal growth and health, and select appropriate timing, mode and location of labour and delivery.

Surveillance and monitoring of maternal and fetal wellbeing in labour requires entities that provide for anticipation, detection and management of fetal distress. Guidelines exist in most jurisdictions based on the evidence base for best practice in obstetric management where maternal wellbeing is compromised or the fetus becomes at risk. Where necessary, advance consultation with centres specializing in obstetric and newborn care should occur for advice regarding ongoing care of the mother and plans for labour and delivery. This may require transport of the mother with the fetus still in utero if care at a higher level is necessary to optimise the chances of healthy delivery and normal fetal outcome. (Jaimovitch \& Vidyasagar 1993; Macnab 1994) An important consideration in this regard is that staff are available with the required skills to comprehensively resuscitate any sick newborn infant and promptly address residual morbidity from premature or complicated delivery; this is known to reduce the risks of brain injury following premature delivery, and in situations where hypoxia and ischemia or any other form of brain injury is considered a potential risk. It also follows that after birth and appropriate resuscitation newborn care entities must be available to minimize the risks of any fetal brain injury being compounded or new injury occurring in the newborn period. Measures to do this include support of respiration and 
circulation, provision of a neutral thermal environment, hydration and nutrition, use of prophylactic antibiotics and management of proven infections, haematological and biochemical monitoring and neuroradiological studies, and appropriate discharge planning and follow up.

\section{References}

[1] Alkalay A.L., H.B. Sarnat, L. Flores-Sarnat, \& C. F Simmons, "Neurologic aspects of hypoglycemia', IMAJ, 7, 188-192 (2005a)

[2] Alkalay A.L., L. Flores-Sarnat, H.B. Sarnat, F.G. Moser \& C. F Simmons, "Brain Imaging Findings in Neonatal Hypoglycemia: Case Report and Review of 23 Cases", Clinical Pediatrics, 44(9), 783-790 (2005b)

[3] Al-Rawi P.G., "Near infrared spectroscopy in brain injury: today's perspective", Acta Neurochir Suppl, 95, 453-457, (2005)

[4] American College of Obstetricians and Gynecologists, "ACOG practice bulletin. Clinical management guidelines for obstetrician-gynecologists. Number 70. Intrapartum fetal heart rate monitoring", Obstetrics and Gynecology, 106, 1453-1460 (2005)

[5] American College of Obstetricians and Gynecologists, American Academy of Pediatrics. Neonatal encephalopathy and cerebral palsy: defining the pathogenesis and pathophysiology. Washington, DC: American College of Obstetricians and Gynecologists; 2003

[6] Anderson P.J. \& L.W. Doyle, "Cognitive and educational deficits in children born extremely preterm", Seminars in Perinatology, 32(1), 51-58 (2008)

[7] Asrat T., "Intra-amniotic infection in patients with preterm prelabor rupture of membranes. Pathophysiology, detection, and management", Clin Perinatol, 28(4), 735-751 (2001)

[8] Aubry M.C., J.P. Aubry \& M. Dommergues, "Sonographic prenatal diagnosis of central nervous system abnormalities", Childs Nerv Syst, 19, 391-402 (2003)

[9] Austin M., "To treat or not to treat: maternal depression, SSRI use in pregnancy and adverse neonatal effects", Psychological Medicine, 36, 1663-1670 (2006)

[10] Back S.A. \& S.A Rivkees, "Emerging concepts in periventricular white matter injury" Semin Perinatol, 28(6), 405-14 (2004)

[11] Barkovich A.J., F.S. Ali, H.A. Rowley \& N. Bass, "Imaging patterns of neonatal hypoglycemia", AJNR Am J Neuroradiol, 19, 523-528 (1998)

[12] Barks J.D.E. \& F.S. Silverstein, "Inflammation and neonatal brain injury" (Eds) S.M. Donn, S.K. Sinha \& M.L. Chiswick, Birth asphyxia and the brain: Basic science and clinical implications, Futura Publishing Company, Armonk NY, 71-88 (2002)

[13] Bashiri A., E. Burstein \& M. Mazor, "Cerebral palsy and fetal inflammatory response syndrome: a review", J Perinat Med, 34, 5-12 (2006)

[14] Bergh T, A Ericson, T Hillensjö, KG Nygren \& UB Wennerholm, "Deliveries and children born after in-vitro fertilization in Sweden 1982-95 a retrospective cohort study", Lancet, 354, 1579-1585 (1999)

[15] Beyene S.V., P, Shah \& M. Perlman, "Association between hematologic findings and brain injury due to neonatal hypoxic-ischemic encephalopathy", Am J Perinatol, 26(4), 285-302 (2009) 
[16] Brady K.M., J.K. Lee, K.K. Kibler. P.S. Smielewski, M. Czosnyka, R.B. Easley, R.C. Koehler \& D.H. Shafner, “Continuous time-domain analysis of cerebrovascular autoregulation using near-infrared spectroscopy", Stroke, 38, 2818-2825 (2007)

[17] Burns C.M., M.A. Rutherford, J.P. Boardman \& F.M. Cowan, "Patterns of cerebral injury and neurodevelopmental outcomes after symptomatic hypoglycemia", Pediatrics, 122(1), 65-74 (2008)

[18] Canavan T.P., H.N. Simhan \& S. Caritis, "An evidence-based approach to the evaluation and treatment of premature rupture of membranes: Part 11", JAMA, 59(9), 678-689 (2004)

[19] Chen S., K. Sakatani, W. Lichty, P. Ning, S. Zhao \& H, Zuo, “Auditory-evoked cerebral blood oxygenation changes in hypoxic-ischemic encephalopathy of newborn infants monitored by near infrared spectroscopy", Early Hum Dev, 67, 113-122 (2002)

[20] Counsell S.J., Tranter S.L. \& Rutherford M.A., "Magnetic resonance imaging of brain injury in the high-risk term infant", Seminars Perinatol, 34(1), 67-78 (2010)

[21] Cowan F., M. Rutherford, F. Groenendaal, P. Eken, E. Mercuri, G. M. Bydder, L. C. Meiners, L. M.S. Dubowitz \& L.S. de Vries, “Origin and timing of brain lesions with neonatal encephalopathy", Lancet, 361(9359), 736-742 (2003)

[22] De Haan T.R., G.V. Wezel-Meijler, M. F. C. Beersma, J.S. von Lindern, S. G. Van Duinen \& F. J. Walther, "Fetal stroke and congenital parvovirus B19 infection complicated by activated protein C resistance", Acta Paediatrica, 95(7), 863-867 (2006)

[23] Dow-Edwards D. L., “Cocaine effects on fetal development: A comparison of clinical and animal research findings," Neurotoxicol Teratol, 13(3), 347-352 (1991)

[24] Efron D., M. South, J.J. Volpe \& T. Inder, "Cerebral injury in association with profound iatrogenic hyperglycemia in a neonate", Eur J Ped Neurol, 7, 167-171 (2003)

[25] Ehrenberg H.M. \& B.M. Mercer, "Antibiotics and the management of preterm premature rupture of the fetal membranes", Clin Perinatol, 28(4), 807-818 (2001)

[26] Feigin V., N. Anderson, A. Gunn, A. Rogers, \& C. Anderson, "The emerging role of therapeutic hypothermia in acute stroke", Lancet Neurol, 2, 529 (2004)

[27] Fellman V. \& A.K. Raivio, "Reperfusion injury as the mechanism of brain damage after perinatal asphyxia", Pediatr Res, 41, 599-606 (1997)

[28] Ferrari M., D.A. Wilson, D.F. Hanley \& R.J. Traystman, “Effects of graded hypotension on cerebral blood flow, blood volume, and mean transit time in dogs", Am J Physiol, 262(6), H1908-H1914 (1992)

[29] Ferrari M., L. Mottola \& V. Quaresima, "Principles, techniques and limitations of near infrared spectroscopy", Can J Appl Physiol, 29(4), 463-487 (2004)

[30] Ferrari M., M. Muthalib \& V Quaresima, "The use of near-infrared spectroscopy in understanding skeletal muscle physiology: recent developments", Phil Trans R Soc A, 369, 4577-4590 (2011)

[31] Ferriero D.M., "Neonatal brain injury", New Engl J Med, 351(19), 1985-95 (2004)

[32] Filly R.A., R.B. Goldstein \& P.W. Callen, "Fetal ventricle: importance of routine obstetric sonography", Radiology, 181, 1-7 (1991)

[33] Francis F., G. Meyer, C Fallet-Bianco, S. Moreno, C. Kappeler, A. Cabrera Soccorro, F P.D. Tuy, C. Beldjord \& J. Chelly, "Human disorders of cortical development: from past to present", Eur J Neurosci, 23, 877-893 (2006) 
[34] Gagnon R.E., A. Leung, A.J. Macnab “Variations in regional cerebral blood volume in neonates associated with nursery care events", Am J Perinatol, 16(1), 7-11 (1999)

[35] Garite T.J., "Management of premature rupture of membranes" Clin Perinatol, 28(4), 837-847 (2001)

[36] Gerdes J.S., “Diagnosis and management of bacterial infections in the neonate', Pediatr Clin N Am, 51, 939-959 (2004)

[37] Gilbert W.M., B.N. Jacoby, G. Xing, B. Danielsen \& L.H. Smith, "Adverse obstetric events are associated with significant risks of cerebral palsy", Am J Obstet Gynecol, 204(5), e15-6 (2011)

[38] Ginsberg M.D. \& R.E. Meyers, "Fetal brain damage following maternal carbon monoxide intoxication: an experimental study", Acta Obstet Gynec Scand, 53, 309317 (1974)

[39] Glenn G.A \& Barkovich A.J., "Magnetic resonance imaging of the fetal brain and spine: an increasingly important tool in prenatal diagnosis, Part 1", Am J Neuroradiol, 27:1604-1611 (2006)

[40] Goodwin T.M., I. Belai, P. Hernandez, M. Durand \& R.H. Paul, "Asphyxial complications in the term newborn with severe umbilical acidemia", Am J Obstet Gynecol, 167, 637-641 (1992)

[41] Gotsch F., R. Romero, J.P. Kusanovic, S. Mazaki-Tovi, B.L. Pineles, O. Erez, J. Espinoza \& S.S. Hassan, "The fetal inflammatory response syndrome" Clin Obstet Gynecol, 50(3), 652-83 (2007)

[42] Graham E.M., Ruis K.A., Hartman A.L., Northington F.J. \& Fox H.E., “A systematic review of the role of intrapartum hypoxia-ischemia in the causation of neonatal encephalopathy", Am J Obstet Gynecol. 199(6):587-952 (2008)

[43] Grether J.K. \& K. B. Nelson, "Maternal infection and cerebral palsy in infants of normal birth weight", JAMA, 278(3), 207-211 (1997)

[44] Guay J. \& J Lachapelle, "No evidence for superiority of air or oxygen for neonatal resuscitation: a meta- analysis", Can J Anesth, doi 10.1007/s12630-011-9589-0 (2011)

[45] Gunn A.J., Cerebral hypothermia for prevention of brain injury following perinatal asphyxia", Current Opinion in Pediatrics, 12(2), 111-115 (2000)

[46] Gunn A.J., \& P.D. Gluckman, "Head cooling for neonatal encephalopathy: The state of the art", Clinical Obstetrics and Gynecology, 50(3), 636-651 (2007)

[47] Hagberg H. \& C. Mallard, "Antenatal brain injury: aetiology and possibilities of prevention", Seminars in Neonatology, 5(1), 41-51 (2000)

[48] Haldane J.S., "Respiration", Yale University Press, New Haven (1922).

[49] Halopainen I.E. \& H.B. Lauren, "Glutamate signaling in the pathophysiology and therapy of prenatal insults", Pharmacol Biochem Behav, (2011), doi:10.1016/j.pbb.2011.03.016

[50] Hamaoka T., K.K. McCully, V. Quaresima, Y. Yamamoto \& B Chance. "Near-infrared spectroscopy/imaging for monitoring muscle oxygenation and oxidative metabolism in healthy and diseased humans", J Biomed Optics, 12(6), 062105 (2007)

[51] Hankins G.D. V., Koen S., Gei A.F., Lopez S. M., Van Hoek J. W., Anderson G.D., "Neonatal organ system injury in acute birth asphyxia sufficient to result in neonatal encephalopathy. Obstet Gynecol, 99, 688-91 (2002) 
[52] Hansen M., J. J. Kurinczuk, C. Bower \& Sandra Webb, “The Risk of Major Birth Defects after Intracytoplasmic Sperm Injection and in Vitro Fertilization", N Engl J Med, (346), 725-730 (2002)

[53] Hatten M.E., "New directions in neuronal migration”, Science, 297, 1660-1663 (2002)

[54] Heffner L.J., "Advanced maternal age- How old is too old?" N Engl J Med, 351, 19271929 (2004)

[55] Helwig J.T., J.T. Parer, S.J. Kilpatrick \& R.K. Laros, “Umbilical cord acid-base state: What is normal?" Am J Obstet Gynecol, 174(6), 1807-1814 (1996)

[56] Higgins R., T.N.K. Rau, J. Perlman, D.V. Azzopardi, L.R. Blackmon, R.H. Clark, A.D. Edwards, D.M. Ferriero, P.D. Gluckman, A.J. Gunn, S.E. Jacobs, D Jenkins-Eicher, A.H. Jobe, A.R. Laptook, M.H. LeBlanc, C. Palmer, S. Shankaran, R.F. Soll, A.R. Stark, M.Thoresen, J. Wyatt, \& the hypothermia workshop speakers and discussants, "Hypothermia and perinatal asphyxia: executive summary of the National Institute of Child Health and Human Development workshop", J. Pediatr, $148,170-175$ (2006)

[57] Hoshi Y., "Functional near-infrared spectroscopy: current status and future prospects," J Biomed Optics, 12(6), 062106, (2007)

[58] Huang B.J. \& M. Castillo, “Hypoxic-ischemic brain injury: imaging findings from birth to adulthood", Radiographics, 28, 417-439 (2008)

[59] Jablonski N., "Skin. A natural history", University of California Press (2006)

[60] Jaimovich D.G. \& G. Vidyasagar, "Transport medicine”, Pediatr Clin N Am, 40(2), (1993)

[61] Karimzadeh P., S. Tabarestani \& M. Ghofrani, Hypoglycemia-occipital syndrome: A specific neurologic syndrome following neonatal hypoglycemia?", J Child Neurol, 26, 152-159 (2011)

[62] Kendall G. \& D. Peebles, "Acute fetal hypoxia: the modulating effect of infection", Early Hum Dev, 81, 27-34 (2005)

[63] Khwaja O. \& J.J. Volpe, "Pathogenesis of cerebral white matter injury of prematurity", Arch Dis Child Fetal Neonatal Ed, 93, F153-F161 (2008)

[64] Kilbride H.W. \& D.W. Thibeault, "Neonatal complications of preterm premature rupture of membranes. Pathophysiology and management", Clin Perinatol, 28(4), 761-785 (2001)

[65] Lapointe A. \& K.J. Barrington, "Pulmonary hypertension and the asphyxiated newborn", J Pediatr, 158, e19-24 (2011)

[66] Larroche J.C., F. Encha-Razavi, \& F. de Vries, "Central nervous system”, Ed. E GilbertBarnes (ed) Potter's pathology of the fetus and infant, Mosby, St. Louis, 1028-1150 (1997)

[67] Lattimore K.A., S.M. Donn, N. Kaciroti, A.R. Kemper, C.R. Neal \& D.M. Vazquez, "Selective serotonin reuptake inhibitor (SSRI) use during pregnancy and effects on the fetus and newborn: A meta-analysis", J Perinatol, 25, 595-604 (2005)

[68] Law, K.L. L.R. Stroud, L.L. LaGasse, R. Niaura, J. Liu \& B.M. Lester, “Smoking during pregnancy and newborn neurobehavior", Pediatrics, 111, 1318-1323 (2003)

[69] Lee S.E., R. Romero, H. Jung, C.W. Park, J.S. Park JS \& B.H. Yoon. "The intensity of the fetal inflammatory response in intraamniotic inflammation with and without microbial invasion of the amniotic cavity', Am J Obstet Gynecol, 197(3), 294.e1-294.e6 (2007) 
[70] Limperopoulos C., R.L. Robertson, N.R. Sullivan, H. Bassan \& A.J. du Plessis, "Cerebellar injury in term infants: clinical characteristics, magnetic resonance imaging findings and outcome", Pediatr Neurol, 41(1), 1-8 (2009)

[71] Lin P. Y., S.I. Lin, T. Penney \& J.J. Chen, "Applications of near infrared spectroscopy and imaging for motor rehabilitation in stroke patients", J Med Biol Eng, 29(5), 210$221(2009)$

[72] Liston R.M., D. Sawchuck \& D. Young, "Fetal health surveillance: Antepartum and intrapartum consensus guideline", J Obs Gyn Canada, 29(9, Suppl 4), S3-S56 (2007)

[73] Logitharajah P., M.A. Rutherford \& F.M. Cowan, "Hypoxic-ischemic encephalopathy in preterm infants: antecedent factors, brain imaging, and outcome", Pediatr Res, 66(2), 222-229 (2009)

[74] Lotzoff B. \& M.K. Georgieff, "Iron deficiency and brain development", Seminars in Pediatric Neurology, 13(3), 158-165 (2006)

[75] Low J.A., B.G. Lindsay \& J. Derrick, “Threshold of metabolic acidosis associated with newborn complications", Am J Obstet Gynecol, 177, 1391-1394 (1997)

[76] Macnab A.J., "Paediatric interfacility transport: Standards of care, organization and principles", Pediatr Anaesth, 4, 351-357 (1994)

[77] Macnab A.J., R.E. Gagnon \& F.A. Gagnon, “Near infrared spectroscopy for intraoperative monitoring of the spinal cord", Spine, 27(1), 17-20, (2002)

[78] Macnab A.J., R.E. Gagnon, F.A. Gagnon \& J. LeBlanc, “NIRS monitoring of brain and spinal cord: Detection of adverse intraoperative events", Spectroscopy, 17, 483-490, (2003)

[79] Macnab A.J., "Biomedical applications of near infrared spectroscopy", Eds. A. Barth \& P.I. Haris, Biological and Biomedical Spectroscopy Volume 2 Advances in Biomedical Spectroscopy, IOS Press, Amsterdam, 305-402 (2009)

[80] Macones G.A., G.D. Hankins, C.Y. Spong, J. Hauth \& T. Moore, "The 2008 national institute of child health and human development workshop report on electronic fetal monitoring: Update on definitions, interpretation, and research guidelines", JOGNN, 37, 510-515 (2008)

[81] Malaeb S. \& O. Dammann, "Fetal inflammatory response and brain injury in the preterm newborn", J Child Neurol, 24, 1119-1126 (2009)

[82] Marin O. \& J.L. Rubenstein, "Cell migration in the forebrain", Annu Rev Neurosci, 26, 441-483 (2003)

[83] Mathur A.M., Neil J.J. \& Inder T.E., “Understanding brain injury and neurodevelopmental disabilities in the preterm infant: the evolving role of advanced magnetic resonance imaging", Seminars Perinatol, 34(1):57-66 (2010)

[84] Mercer B.M., "Preterm premature rupture of the membranes: diagnosis and management", Clin Perinatol, 31, 765-782 (2004)

[85] Meyers R.E., "Two classes of dysergic brain abnormality and their conditions of occurrence", Arch Neurol, 29, 394-399 (1973)

[86] Meyers R.E., "Four patterns of perinatal brain damage and their conditions of occurrence in primates", (Eds) B.S. Meldrum \& C.D. Marsden, Advances in Neurology volume 10, Raven Press, New York (1975)

[87] Meyers R.E., "Fetal asphyxia due to umbilical cord compression: metabolic and brain pathologic consequences", Biol Neonate, 26(1-2), 21-43 (1975) 
[88] Murkin J.M. \& M. Arango, “Near-infrared spectroscopy as an index of brain and tissue oxygenation", Br J Anaesth, 103 (Suppl. 1), i3-i13, (2009)

[89] Nelson K.B. \& J.H. Ellenberg, "Apgar scores as predictors of chronic neurologic disability", Pediatrics, 68, 36-44 (1981)

[90] Oberlander T.F., W. Warburton, S. Misri, J. Aghajanian \& C. Hertzman, "Neonatal outcomes after prenatal exposure to selective serotonin reuptake inhibitor antidepressants and maternal depression using population-based linked health data", Arch Gen Psychiatry,63, 898-906 (2006)

[91] O'Callaghan M.E., A.H. MacLennan, C.S. Gibson, G.L. McMichael, E.A. Haan, J.L. Broadbent, P.N. Goldwater, \& G.A. Dekker, for the Australian Collaborative Cerebral Palsy Research Group, Epidemiologic associations with cerebral palsy", Obstetrics and Gynecology, 118(3), 576-582, (2011)

[92] Okereafor A., J. Allsop, S.J. Counsell, J. Fitzpatrick, D. Azzopardi, M.A. Rutherford \& F.M. Cowan, "Patterns of brain injury in neonates exposed to perinatal sentinel events", Pediatrics, 121, 906-914 (2008)

[93] Oudijk M.A., R.H. Gooskens. P. Stoutenbeek, L.S. De Vries, G.H. Visser \& E.J. Meijbooms, "Neurological outcome of children who were treated for fetal tachycardia complicated by hydrops", Ultrasound Obstet Gynecol, 24, 154-158 (2004)

[94] Owen-Reece H., M. Smith, C.E. Elwell \& J.C. Goldstone, "Near infrared spectroscopy", Br J Anaesth, 82, 418-26, (1999)

[95] Ozduman K., B. R Pober, P. Barnes, J. A. Copel, E.A.Ogle, C.C. Duncan \& L. R Ment, "Fetal Stroke", Ped Neurol, 30(3), 151-162 (2004)

[96] Perlman J.M., "Interruption of placental blood flow during labor: potential systemic and cerebral organ consequences", J Pediatr, 158, e1-4 (2011)

[97] Perlman M. \& P.S. Shah, "Hypoxic ischemic encephalopathy: challenges in outcome and prediction", J Pediatr, 158, e51-54 (2011)

[98] Phelan J. P., L. M. Korst, \& G. I. Martin, “Application of Criteria Developed by the Task Force on Neonatal Encephalopathy and Cerebral Palsy to Acutely Asphyxiated Neonates", Obstet Gynecol, 118(4), 824-830 (2011)

[99] Porat S., E.Y. Anterby, Y. Hamani \& S. Yagel, "Fetal supraventricular tachycardia diagnosed and treated at 13 weeks of gestation: a case report", Ultrasound Obstet Gynecol, 21, 302-305 (2003)

[100] Razic P., "Evolving concepts of cortical radial and areal specification", Progr Brain Res, 136, 265-280 (2002)

[101] Rees S. \& T. Inder, "Fetal and neonatal origins of altered brain development", Early Human Development, 81(9), 753-761 (2005)

[102] Riley E.P. \& C.L. McGee, "Fetal alcohol spectrum disorders: An overview with emphasis on changes in brain and behavior", Exp Biol Med, 230(60), 357-365 (2005)

[103] Robertson C.M.T. \& M. Perlman, "Follow-up of the term infant after hypoxic-ischemic encephalopathy", Paediatr Child Health, 11(5) 278-282 (2006)

[104] Roland E.H., A. Hill, M.G. Norman, O. Flodmark \& A.J. Macnab, “Selective brainstem injury in an asphyxiated newborn", Ann Neurol, 23(1), 89-92 (1988)

[105] Roland E.H., K. Poskitt, E. Rodriguez, B.A. Lupton \& A. Hill, "Perinatal hypoxicischemic thalamic injury: clinical features and neuroimaging", Ann Neurol, 44(20), 161-166 (1998)

[106] Rolfe P., “In vivo near-infrared spectroscopy”, An Rev Biomed Eng, 2, 715-754 (2000) 
[107] Royal College of Obstetricians and Gynaecologists, “The use of electronic fetal monitoring. The use and interpretation of cardiotocography in intrapartum fetal surveillance. Evidence-based clinical practice guideline number 8. Clinical effectiveness support unit. London, UK: Royal College of obstetricians and Gynaecologists Press. www.rcog.org.uk/resources/public/pdf/efm.guideline.final2may2001.pdf (2005)

[108] Ruis K.A., K.A. Ruis, C.U. Lehmann, F.J. Northington, F.J. Lin \& E.M. Graham, "Neonatal brain imaging and the identification of metabolic acidemia and hypoxicischemic encephalopathy", J Matern Fetal Neonatal Med, 22(10), 823-828 (2009)

[109] Sakatani K., Y. Xie, W. Lichty, S. Li \& H. Zuo, “Language-activated cerebral blood oxygenation and hemodynamic changes of the left prefrontal cortex in post stroke aphasic patients: a near infrared spectroscopy (NIRS)", Stroke, 29, 1299-1304(1998)

[110] Sarnat H.B. \& Sarnat M.S., "Neonatal encephalopathy following fetal distress: a clinical and electroencephalographic study", Arch Neurol, 33(10), 696-705 (1976)

[111] Schieve L.A., S. F. Meikle, C. Ferre, H. B. Peterson, G Jeng \& L. S. Wilcox, "Low and Very Low Birth Weight in Infants Conceived with Use of Assisted Reproductive Technology", N Engl J Med, (346), 731-737 (2002)

[112] Schulzke S.M., S. Rao \& S.K. Patole, "A systematic review of cooling for neuroprotection in neonates with hypoxic ischemic encephalopathy - are we there yet?", BMC Pediatrics, 7, 30 (2007) doi: 10.1186/1471-2431-7-30

[113] Shadgan B., Reid W. D., Gharakhanlou R., Stothers L. \& Macnab A. J., “Wireless nearinfrared spectroscopy of skeletal muscle oxygenation and hemodynamics during exercise and ischaemia", Spectroscopy, 23 233-41 (2009)

[114] Simonson S.G. \& C.A. Piantadosi, "Near-infrared spectroscopy, clinical applications", Crit Care Clin, 12(4), 1019-1029, (1996)

[115] Stromberg B., G. Dahlquist, A. Ericson, O. Finnstrom, M. Koster \& K Stjernqvist, "Neurological sequelae in children born after in-vitro fertilization: a population based study", Lancet, 360(9344), 718-719 (2002)

[116] Sukhov A., Y. Wu, G. Xing, L.H. Smith \& W.M. Gilbert, "Risk factors associated with cerebral palsy in preterm infants", J Mat Fetal Neonatal Med, doi:10.3109/14767058.2011.564689 (2011)

[117] Suzuki S., S. Takasaki, T. Ozaki \& Y. Kobayashi, “A tissue oxygenation monitor using NIR spatially resolved spectroscopy", Proc SPIE, 3597, 582-592 (1999)

[118] Tasker R.C., "Seizures” Eds. A.J. Macnab, D.J Macrae \& R. Henning. Care of the critically ill child. Churchill Livingstone London, Toronto, New York. (2001)

[119] Tobias J.D., "Cerebral oxygenation monitoring: near-infrared spectroscopy", Expert Rev Med Devices, 3(2), 235-243, (2006)

[120] Todd K.G., L.L. Jantzie \& P. Cheung, “Oxidative stress in neonatal hypoxic-ischemic encephalopathy", Eds. N. Gadoth \& H.H. Gobel, Oxidative stress and free radical damage in neurology. Oxidative stress in applied basic research and clinical practice, 4763 doi: 10.1007/978-1-60327-514-9_4 Springer Science and Business Media LLC (2011)

[121] Vannucci R.C. \& J.M. Perlman, Interventions for perinatal hypoxic-ischemic encephalopathy. Pediatrics, 100, 1004-1014 (1997)

[122] Volpe J.J., "Brain injury in the premature infant - from pathogenesis to prevention", Brain and Development, 19(8), 519-534 (1997) 
[123] Volpe J.J., "Intracranial hemorrhage: Germinal matrix-intraventricular hemorrhage of the premature infant. (Ed) J.J. Volpe, Neurology of the newborn, Fourth Edition, Saunders, Philadelphia, Pa. 428-493 (2001a)

[124] Volpe J.J., "Neurobiology of periventricular leukomalacia in the premature infant", Pediatr Res, 50(5), 533-562 (2001b)

[125] von Bel F., C.A. Dorrepaal, J.N.L. Benders, P.E.M. Zeeuwe, M.V.D. Bor \& H.M. Berger, "Changes in cerebral hemodynamics and oxygenation in the first $24 \mathrm{~h}$ after birth asphyxia", Pediatrics, 92, 365-371 (1993)

[126] Wiberg-Itzel E., C. Lipponer, M. Norman, A, Herbst, D. Prebensen, A. Hansson, A.L. Bryngelsson, M. Christoffersson, M. Sennstrom, U.B. Wennerholm \& L. Nordstrom, "Determination of $\mathrm{pH}$ or lactate in fetal scalp blood in management of intrapartum fetal distress: randomized controlled multicentre trial", BMJ, 336(7656), 1284-1287 (2008)

[127] Wolf M., M. Ferrari \& V. Quaresima, "Progress of near-infrared spectroscopy and topography for brain and muscle clinical applications", J Biomed Optics, 12(6), 062104 (2007)

[128] Wu Y.W., G.J. Escobar, J.K. Grether, L.A. Croen, J.D. Greene \& T.B. Newman, "Chorioamnionitis and cerebral palsy in term and near-term infants", JAMA, 290, 2677-2372 (2003)

[129] Wyatt J.S., "Near infrared spectroscopy in asphyxial brain injury", Clin Perinatol, 20, 369-378 (1993)

[130] Yodh A.G. \& D.A. Boas, “Functional Imaging with diffusing light”, Ed. T. Vo-Dinh, Biomedical Photonics Handbook, CRC Press, Florida, USA, 21-1 - 21-45 (2003)

[131] Yudkin P.L., A. Johnson, L.M. Clover \& K.W. Murphy. "Assessing the contribution of birth asphyxia to cerebral palsy in term singletons", Pediatr Perinatal Epidemiol, 9, $156-70$ (1995) 


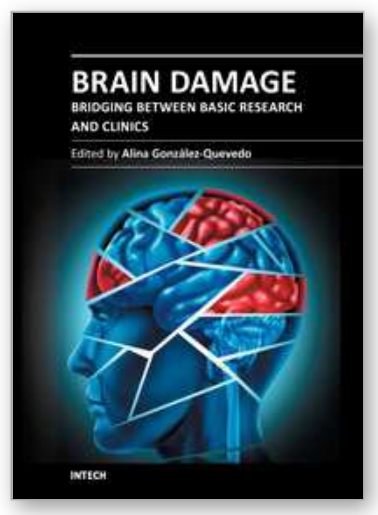

\author{
Brain Damage - Bridging Between Basic Research and Clinics \\ Edited by Dr. Alina Gonzalez-Quevedo
}

ISBN 978-953-51-0375-2

Hard cover, 282 pages

Publisher InTech

Published online 16, March, 2012

Published in print edition March, 2012

"Brain Damage - Bridging Between Basic Research and Clinics" represents a collection of papers in an attempt to provide an up-to-date approach to the fascinating topic of brain damage in different pathological situations, combining the authors' personal experiences with current knowledge in this field. In general, the necessary link between basic and clinical neurosciences is highlighted, as it is through this interaction that the theoretical understanding of the pathophysiological mechanisms can be successfully translated into better ways to diagnose, treat and prevent the catastrophic events that occur when the brain suffers from external or internal noxious events. The book spans different aspects of brain injury, starting from damage occurring in the fetal and child brain, followed by different neurodegenerative processes. Attention is also focused on the negative effects of drug addictions and sleep deprivation on the brain, as well as on the early assessment of brain injury for preventive strategies employing sensitive biomarkers.

\title{
How to reference
}

In order to correctly reference this scholarly work, feel free to copy and paste the following:

Andrew Macnab (2012). The Etiology and Evolution of Fetal Brain Injury, Brain Damage - Bridging Between Basic Research and Clinics, Dr. Alina Gonzalez-Quevedo (Ed.), ISBN: 978-953-51-0375-2, InTech, Available from: http://www.intechopen.com/books/brain-damage-bridging-between-basic-research-and-clinics/theetiology-and-evolution-of-foetal-brain-injury

\section{INTECH}

open science | open minds

\section{InTech Europe}

University Campus STeP Ri

Slavka Krautzeka 83/A

51000 Rijeka, Croatia

Phone: +385 (51) 770447

Fax: +385 (51) 686166

www.intechopen.com

\section{InTech China}

Unit 405, Office Block, Hotel Equatorial Shanghai

No.65, Yan An Road (West), Shanghai, 200040, China

中国上海市延安西路65号上海国际贵都大饭店办公楼 405 单元

Phone: +86-21-62489820

Fax: $+86-21-62489821$ 
(C) 2012 The Author(s). Licensee IntechOpen. This is an open access article distributed under the terms of the Creative Commons Attribution 3.0 License, which permits unrestricted use, distribution, and reproduction in any medium, provided the original work is properly cited. 